\title{
NANOTECHNOLOGY FOR ADVANCED NUCLEAR THERMAL-HYDRAULICS AND SAFETY: BOILING AND CONDENSATION
}

\author{
IN CHEOL BANG ${ }^{1}$ and JI HWAN JEONG ${ }^{2, *}$ \\ ${ }^{1}$ Interdisciplinary School of Green Energy, Ulsan National Institute of Science and Technology (UNIST) \\ 100 Banyeon-ri, Eonyang-eup, Ulju-gun, Ulsan Metropolitan City 689-798, Republic of Korea \\ ${ }^{2}$ School of Mechanical Engineering, Pusan National University \\ 30, Jangjeon-dong, Geumjeong-gu, Busan, 609-735, Republic of Korea \\ ${ }^{*}$ Corresponding author. E-mail : jihwan@pusan.ac.kr \\ Received June 14, 2011
}

A variety of Generation III/III+ water-cooled reactor designs featuring enhanced safety and improved economics are being proposed by nuclear power industries around the world in efforts to solve the future energy supply shortfall. Thermal-hydraulics is recognized as a key scientific subject in the development of innovative reactor systems. Phase change by boiling and condensation in the reverse process is a highly efficient heat transport mechanism that accommodates large heat fluxes with relatively small driving temperature differences. This mode of heat transfer is encountered in a wide spectrum of nuclear systems, and thus it is necessary to determine the thermal limit of water-cooled nuclear energy conversion in terms of economic and safety. Such applications are being advanced with the introduction of new technologies such as nanotechnology. Here, we investigated newly-introduced nanotechnologies relevant to boiling and condensation in general engineering applications. We also evaluated the potential linkage between such new advancements and nuclear applications in terms of advanced nuclear thermal-hydraulics.

KEYWORDS : Boiling, Condensation, Critical Heat Flux, Thermal-hydraulics, Nanotechnology, Nuclear Safety, Heat Transfer Enhancement

\section{INTRODUCTION}

Energy conversion has been a central engineering topic in the development of modern society following the Industrial Revolution. This field of engineering is related to the transformation of energy from sources such as fossil fuels and nuclear fuels and the sun into useful forms such as thermal, mechanical, and electrical energy. Modern energy engineers face numerous choices and challenges related to engineering owing to the global energy crisis and climate change, particularly with regard to heightened demand in terms of economics and environmental safety in energy conversion. The demand is directly connected to the efficiency of energy conversion, which is a measure of the quality of an operation or of the characteristics of a device. In particular, mass production of the most fundamentally essential form of energy, electricity, depends on power plants and factors deeply rooted in thermodynamics, fluid mechanics, and heat transfer [1].

The upper limit of efficiency of a power plant as a heat engine in terms of thermodynamics is defined by the Carnot efficiency, an idea setforth by Sadi Carnot in
1824. It is also called the theoretical limit for efficiency of a heat engine cycle,and is based on the following derived equation: $\eta_{\text {Carnot }}=1-Q_{L} / Q_{H}=1-T_{L} / T_{H}$. The equation states that efficiency rises as $T_{L}$ drops and as $T_{H}$ increases; this clearly means the efficiency of a heat engine will be limited by the maximum attainable energy-source temperature and the lowest available heat-sink temperature. Whereas the Carnot efficiency sets an upper limit on the performance of heat engines and therefore serves as a criterion by which other engines must lower efficiencies in terms of the second law of thermodynamics, it should be noted that current typical power plants must be improved to have higher fuel temperatures (boiling-related) and lower heat sink temperatures (condensation-related) for realizing better conversion. However, thusfar, this has been limited by the heat removal system of energy conversion engineering, or heat transfer (concisely, there is a lack of engineering materials with adequate durability under extreme temperature conditions).

To an energy conversion engineer, efficiency improvement via a new concept for better heat transfer is one of the important challenges in energy conversion 
engineering, particularly with the introduction of nanotechnologies.

In addition, a variety of Generation III/III+ watercooled reactor designs featuring enhanced safety and improved economics are being proposed by nuclear power industries around the world in efforts to solve the future energy supply shortfall. Thermal-hydraulics is recognized as a key scientific subject in the development of innovative nuclear systemscharacterized by passive safety systems. Key crosscutting thermal-hydraulic issues must be faced in various innovative nuclear systems, such as advanced reactor core thermal-hydraulics, single phase mixed convection and turbulence, two-phase flow, and code coupling and validation. This paper is dedicated to a review of boiling and condensation in relation to nuclear applications, particularly in terms of the above-mentioned efficiency improvements with better heat transfer based on phase change.

The importance of the thermal-hydraulic phenomena with phase change (from liquid to vapor) of a coolant in nuclear engineering emerges from the fact that many reactors use a liquid coolant that is subjected to high heat fluxes [4]. Phase change by boiling or evaporation or condensation in the reverse process is a highly efficient heat transport mechanism, which accommodates large heat fluxes with relatively small driving temperature differences. This mode of heat transfer is frequently encountered in a wide spectrum of engineering systems, including thermal energy conversion, air-conditioning and refrigeration, microelectronic cooling, and a variety of micro-devices (microelectromechanical systems (MEMS), micro heat pipes, biochips or lab-on-chips, etc.) that are being developed for new commercial applications[2]. Such applications are being advanced with the introduction of new technologies such as nanotechnology. Here, we investigate widely used nanotechnologies for boiling and condensation. We also evaluate the potential linkage between such new advancements and nuclear applications in terms of advanced nuclear thermal-hydraulics. This avenue of research can be thought of as a hybrid technology of nuclear technology and nanotechnology.

\section{PROCESSES OF PHASE CHANGE IN NUCLEAR SYSTEMS}

Boiling and condensation are processes that are mainly encountered at a solid-liquid interface. Latent heat is the governing effect related with the phase change. The phase change from a liquid to vapor due to boiling (evaporation within a continuous liquid phase) is driven by heat transfer from the solid surface while condensation refers to a process where a gaseous phase substance changes into a liquid phase, and is the reverse of evaporation. Condensation occurs when a gaseous substance loses its internal energy and/or gain pressure, which is higher than the saturation pressure corresponding to the vapor temperature. In general engineering applications, condensation phenomena are associated with thermal energy rejection to a low temperature thermal reservoir or heat sink while boiling phenomena are associated with thermal energy absorption from a high temperature fuel or heat source. Important parameters governing phase change processes are the latent heat $\mathrm{h}_{\mathrm{fg}}$, the surface tension $\sigma$ atthe liquid-vapor interface, and the density difference between the two phases, which causes a buoyancy force. It is well known that,because of coupled latent heat and buoyancy-driven natural convection effects, boiling and condensation heat transfer coefficients are much larger than those of singlephase convection heat transfer without phase change [3]. Therefore, thermal power plants, including nuclear power plants,adopt such higher heat transfer modes for better performance. These characteristics play important roles in nuclear power plants (NPPs), both under normal operation and abnormal operating conditions.

\subsection{Nuclear Power CycleSystems}

The phase change processes are essential to closedloop nuclear power cycles, as thermal power plants are based on the thermodynamic cycle. Pressurized liquid is converted to vapor in a boiler/nuclear core or steam generator. After workingin a turbine, the vapor is restored to its liquid state in a condenser. In boiling water reactors (BWR), the phase change is more systematically incorporated with the system while the nuclear core plays the role of the boiler or steam generator. In a pressurized water reactor (PWR), boiling is utilized in a steam generator while local boiling at the fuel surface in the nuclear core may be permitted at high power to enhance heat transfer [4]. During normal operation, the highpressure secondary coolant, that is, water, is evaporated at the steam generator and expands in turbines to produce boundary work. The exhausted steam goes to a condenser and rejects internal energy and condenses to change into water again. The primary loop of a pressurized water reactor (PWR) has a pressurizer, where primary coolant water evaporates by electric heaters and condenses by a subcooled water spray.

\subsection{Nuclear Safety Systems}

During accident conditions, cooling down the decay heat generated in the reactor core is the most important function in accident management. The decay heat should be transported to a heat sink located inside and ultimately outside the containment. Many engineered safety features are incorporated into NPPs in order to quench the decay heat. Above all, the bounding accident threatening nuclear safety is - although extremely unlikely-a loss-of-coolant accident resulting from a large, double-ended break in the primary coolant system;this has long been considered 
the worst possible accident [5]. As a safety measure, nuclear engineers have designed ECCSs, which are tested in the licensing process to prove that nuclear cores can survive even the worst accident. However, the Three Mile Island accident in 1979 changed the nuclear society's beliefs about successful core cooling or decay heat removal with out core meltdown [6]. In some cases, even if the engineered ECCS is definitely working during an accident, there could be a core melting accident/severe accident, resulting in the possibility of vessel failure due to relocation of the melted core materials in the lower vessel head. Considering the severe accident, in-vessel retention (IVR) of core debris through an external reactor vessel cooling (ERVC) has been implemented for light water reactors (LWRs) [6] [7].

On the other hand, when necessary, a depressurization system (SDS) will dump steam into the water stored in a refueling storage tank (RWST) to reduce the primary-side pressure. In this case, steam will experience direct-contact condensation. If steam is released into a containment building, a containment spray system (CSS) will operate and sprinkle water droplets into the containment atmosphere to condense the stream. Here, some amount of steam comes into contact with the walls of the structures and containment. This steam will condense on the relatively cold wall. A passive secondary condensing system (PSCS) is designed to provide decay heat removal in the case of auxiliary feedwater system (AFS) malfunction. Various designs that specific to the type of NPP have been suggested. The core function of these systems is to condense steam generated by the decay heat. The functionality of these engineered safety features strongly depends on the performance of condensation heat transfer as well as boiling heat transfer. As briefly reviewed above, a nuclear power plant incorporates many heat transfer boundaries such as the fuel cladding surface and reactor external vessel or heat exchanger/ condensers. As the functionality of these systems strongly depends on boiling and condensation performances, effectively enhanced boiling and condensation will contribute to enhanced performance and size reduction of the systems. This can be secured by nanotechnology, as reviewed in the next section.

\section{ADVANCEMENTS OF BOILING AND CONDENSATION USING NANOTECHNOLOGY}

Past research has focused on better understanding of physical phenomena of nuclear thermal-hydraulics, that is, boiling and condensation, and better correlations to predict the phenomena and thereby produce better simulation codes. In addition, with increasing nuclear reactor generation with accompanying emphasis on both economics and safety, systems have changed from active cooling systems to passive cooling systems in order to secure safety. Some advanced systems and components have been introduced to recent generations of reactors.

Of course, enhancement of heat transfer as a key method to improve energy conversion has been continually studied. To this end, typical surface modification techniques with macro- and micro-scales and other numerous active techniques based on external power such as ultrasonic and electro-magnetic fields have been adopted. Represent ative approaches that have been considered to enhance "pool" boiling and critical heat flux $(\mathrm{CHF})$ in particular include [8]: (a) oxidation or selective fouling of a heater surface to increase the wettability of the liquid; (b) vibration of heaters to promote the departure of bubbles from a heater surface; (c) coating or extended heater surface to increase the heat transfer area; (d) heater rotation to promote bubble departure from and liquid deposition onto the heater surface; (e) fluid vibration to promote bubble departure and liquid supply; and (f) application of electric fields to promote bubble departure from the surface by dielectrophoretic force to increase liquid renewal. Among these, surface modification technology such as microscale modulated porous structures has been reviewed by Li et al. [9].

In addition to the above-mentioned methods, nanotechnology has emerged as a new technique in recent years. Nanotechnology is a new approach of manipulating matter on atomic and molecular scales. Generally, with respect to size, nanotechnology involves structures sized between 1 to 100 nanometers in at least one dimension, and includes the development of materials and devices having at least one dimension within that size [10]. Overall, nanotechnology encompasses a wide spectrum of research ranging from extensions of conventional device physics to new approaches rooted in molecular self-assembly;from the fabrication of new materials with dimensions on a nanoscale to investigating whether matter can be directly controlled on an atomic scale [10].

In particular, works introducing nanotechnology to boiling and condensation have been boosted by new developments in nanomaterials having unique properties arising from their nanoscale dimensions. Such works related to boiling and condensation are reviewed in the following sections.

\subsection{Advancements of Boiling Systems}

Nucleate boiling and Critical Heat Flux (CHF) are complex physical phenomena involving numerous thermal and hydrodynamic effects, such as transient conduction, evaporation, two-phase flow, etc.

\subsubsection{Parameters Needed for a Comprehensive Investigation of Pool Boiling and Critical Heat Flux}

\section{(1)Nucleate Boiling Parameters}

At relatively low heat fluxes, nucleate-boiling heat transfer is dominated by the intense agitation and transient 
conduction within the liquid phase near the surface, as bubbles grow and depart from the surface. However, at intermediate to high heat fluxes, close to the $\mathrm{CHF}$, the latent heat of the bubbles becomes the prevalent heat removal mechanism; the heat flux, q", can be written as follows:

$$
q^{\prime \prime}=\frac{\pi D_{b}^{3}}{6} \rho_{g} h_{f g} f_{b} N_{A}
$$

This equation suggests that the bubble departure diameter $\left(D_{b}\right)$, the departure frequency $\left(f_{b}\right)$, and the nucleation site density $\left(\mathrm{N}_{\mathrm{A}}\right)$ are important parameters to describe nucleate boiling. Numerous models and correlations have been proposed in the past for these parameters. For example:

$$
\begin{array}{cc}
D_{b}=0.0208 \theta\left[\frac{\sigma}{g\left(\rho_{f}-\rho_{g}\right)}\right]^{1 / 2} \quad \text { Fritz [11] } \\
f_{b} D_{b}=0.59\left[\frac{\sigma g\left(\rho_{f}-\rho_{g}\right)}{\rho_{f}^{2}}\right]^{1 / 4} \quad \text { Zuber[12] } \\
N_{A}=5 \times 10^{-27}(1-\cos \theta) / d_{c}^{6}, \\
d_{c}=\frac{4 \sigma T_{s a t}}{\rho_{g} h_{f g} \Delta T_{s}} \quad \text { Wang and Dhir[13] }
\end{array}
$$

where, in addition to the thermo-physical and thermodynamic properties, the contact angle $(\theta)$ and the surface superheat $\left(\Delta \mathrm{T}_{\mathrm{s}}\right)$ also appear. The contact angle, which is a measure of the wettability of a surface, deserves particular attention in the case of nanofluid boiling for the following reason. For a generic rough surface, the contact angle can be found from this modified form of Young's equation:

$$
\cos \theta=\mathrm{r} \frac{\gamma_{\mathrm{SV}}-\gamma_{\mathrm{SL}}}{\sigma} \quad \text { Wenzel [14] }
$$

where $r$ is a roughness factor, defined as the ratio of the effective (rough) contact area to the smooth contact area, and $\gamma_{\mathrm{SV}}-\gamma_{\mathrm{SL}}$ is the so-called adhesion tension of the surface materials.

Capillarity, another effect related to surface wettability, can be explained by the following relation for capillary wicking height.

$$
L_{c}=2 \sigma \cos \theta / \rho g r
$$

\section{(2) CHF Parameters}

Despite several decades of intense study, consensus on the explanation of the physical mechanism causing CHF has yet to be attained, even for the simple situation of a pure fluid. Most hypotheses fall into one of the following four categories [26, 50]:

A) Hydrodynamic instability theory, which postulates that CHF occurs when the downflow of a fresh liquid to the heated surface is prevented by the rising vapor (Kutateladze and Leont'ev [15];
Zuber[16]). The CHF is calculated as:

$$
q_{C H F}^{\prime \prime}=C \cdot h_{f g} \rho_{g}^{1 / 2} \sigma^{1 / 4} g^{1 / 4}\left(\rho_{f}-\rho_{g}\right)^{1 / 4}
$$

where $\mathrm{C}$ is an empirical constant depending on the geometry of the heater. The hydrodynamic instability theory notably excludes any effect of the heated surface characteristics (i.e., roughness, wettability, etc.) on the CHF, and for this reason has come under well-substantiated criticism in recent years (see, for example, [Theofanous et al [17]]).

B) Macrolayer dryout theory, which assumes that the $\mathrm{CHF}$ is the result of dryout of a liquid macrolayer under large mushroom-shaped bubbles hovering above the heated surface for a relatively long time before departing [Haramura and Katto[18]]. The $\mathrm{CHF}$ is calculated as:

$$
q_{C H F}=\rho_{f} h_{f g} \delta_{e}(1-\alpha) f_{m}
$$

where $\alpha$ is the void fraction at the surface, $f_{m}$ is the departure frequency of the mushroom bubble, and an expression for the macrolayer thickness (de) has been proposed by Sadisivian et al. [19]:

$$
\delta_{e}=0.5\left(N_{A}\right)^{-0.5}\left[\cos \theta-\frac{\pi}{12}\left(3 \cos \theta-\cos ^{3} \theta\right)\right]
$$

which shows the importance of the contact angle.

C) Hot/dry spot theory, which assumes that CHF occurs due to an irreversible temperature excursion within localized hot/dry spots on the surface [Theofanous et al.[17]]. Theofanous and Dinh [20] considered the microhydrodynamics of the solid-liquid-vapor line at the boundary of a hot/dry spot and calculated the $\mathrm{CHF}$ as:

$$
q_{C H F}^{\prime \prime}=k^{-1 / 2} h_{f g} \rho_{g}^{1 / 2} \sigma^{1 / 4} g^{1 / 4}\left(\rho_{f}-\rho_{g}\right)^{1 / 4}
$$

Interestingly, this equation and the hydrodynamic theory equation are essentially the same, except for the parameter $\mathrm{k}$, which according to Theofanous and Dinh [20] "for a well-wetting surface is smaller than for a poorly-wetting surface"; i.e., everything else being the same, a well-wetting surface will have a higher $\mathrm{CHF}$ than a poorly-wetting surface $[26,50]$.

D) Bubble interaction theory, which postulates that CHF occurs when at high heat flux the bubble number and departure frequency become so high that the bubbles coalesce radially, thus preventing liquid access to the surface [Rosenhow and Griffith, [21]]. Another interesting model was suggested by Kolev [22], who considered the shear force generated by the mutual interaction of the growing and departing bubbles, and the effect 
that such shear force has on nucleate boiling near the CHF. According to Kolev's model [22], the nucleate-boiling heat flux near the CHF can be expressed as follows:

$$
q^{\prime \prime} \propto N_{A}^{1 / 4} \Delta T_{s}^{2}\left(1+0.3 \frac{\Delta \tau_{w}}{\Delta \tau_{d}}\right)^{-1 / 2}
$$

This emphasizes the role of the bubble wait time $\left(\Delta \tau_{\mathrm{w}}\right)$ and departure time $\left(\Delta \tau_{\mathrm{d}}\right)$, as well as the role of the surface conditions, including the contact angle, via the nucleation site density $[26,50]$.

In addition to the well-known $\mathrm{CHF}$ predictions listed above, one of the well-known CHF prediction models considering the surface condition in terms of contact angle (surface wettability) is Kandlikar's CHF prediction model [23], which is based on force balance on a bubble.

$$
\begin{array}{r}
q_{C}^{\prime \prime}=h_{f g} \rho_{g}^{1 / 2}\left(\frac{1+\cos \beta}{16}\right)\left[\frac{2}{\pi}+\frac{\pi}{4}(1+\cos \theta) \cos \varphi\right]^{1 / 2} \\
{\left[\sigma g\left(\rho_{f}-\rho_{g}\right)\right]^{1 / 4}}
\end{array}
$$

For conventional surface modification-based CHF enhancement such as in micro-porous structures, Liter and Kaviany [24] suggested a modified hydrodynamic instability model as a $\mathrm{CHF}$ prediction model for porous heated surfaces, delineated as follows.

$$
\begin{aligned}
\frac{q_{\text {porous }}^{\prime \prime}}{\frac{\pi}{24} \rho_{g}^{1 / 2} h_{f g}\left[g \sigma\left(\rho_{f}-\rho_{g}\right)\right]^{1 / 4}} & =\left(\frac{9}{2 \pi} \frac{\lambda_{R T, c}}{\lambda_{m}}\right)^{1 / 2} \\
& =\frac{3\left[\sigma / g\left(\rho_{f}-\rho_{g}\right)\right]^{1 / 4}}{\lambda_{m}^{1 / 2}} \\
q_{\text {porous }}^{\prime \prime} & =\frac{\pi}{8} h_{f g}\left(\frac{\sigma \rho_{g}}{\lambda_{m}}\right)^{1 / 2}
\end{aligned}
$$

Park et al. [25] corrected the macrolayer thickness of the dryout model suggested by Sadisivian et al. [1992] to consider a porous layer filled with liquid as follows.

$$
\begin{gathered}
\delta_{\text {total }}=r_{b}\left[\cos \theta-\frac{\pi}{12}\left(3 \cos \theta-\cos ^{3} \theta\right)\right]+\varepsilon \delta_{\text {porous }} \\
q_{C H F}^{\prime \prime}=\frac{\delta_{e} \rho_{f} h_{f g}}{\tau_{d}}
\end{gathered}
$$

Review of the traditional models has led to the following list of parameters governing nucleate boiling and $\mathrm{CHF}$ [26]:

- Thermodynamic and thermophysical properties

- Liquid density, viscosity, thermal conductivity, and specific heat

- Vapor density

- Surface tension
- Enthalpy of vaporization

- Vapor tension

- Surface conditions

- Roughness

- Microcavities

- Contact angle (wettability)

- Nucleation site density

- Near-surface hydrodynamics

- Bubble size

- Bubble departure frequency

- Hot/dry spot dynamics

Therefore, researchers have begun to expect that some nanomaterials can enhance thermodynamic and thermophysical properties, surface conditions, and hydrodynamics such that higher boiling heat transfer can be obtained or the limit of nucleate boiling, critical heat flux can be increased.

The methods to introduce nanomaterials (nanoparticles) to the regimes of boiling can be classified into two categories: (i) surface modification with nanomaterials on a nanoscale, and (ii) fluid modification with nanomaterials. In particular, fluid modification is related to the development of tunable coolants desirable for nuclear applications. For example, nuclear coolants should have the requirements for nuclear reactors. These requirements have been summarized by RuzwanAhmed [27] as follows.

- High heat transport and transfer coefficient

- Low pumping power

- Low melting point

- High boiling point

- Non-corrosive properties

- Low neutron absorption cross section

- High moderating ratio.(for thermal reactors)

- Radiation stability

- Thermal stability

- Low induced radioactivity

- No reaction with turbine working fluid

Nevertheless, many studies have focused solely on the heat transfer coefficient.

\subsubsection{Surface Modification Technology (Nanotechnology)}

Typically, surface modification technology has been considered as a means to enhance boiling heat transfer/ critical heat flux. With this approach, the heating surface conditions related to boiling mechanisms or key parameters, as listed above, are modified. Most research related to surface modification has conventionally focused on increasing the surface roughness via coating with appropriate microstructures[28].

Such modification generally increases the surface roughness and the number of micro-cavities, thus including the nucleation site density, resulting in enhancement of boiling heat transfer (BHT). On the other hand, from the viewpoint of critical heat flux, the modification can 
control the contact angle of the liquid on the surface, resulting in changed surface wettability. These surface parameters can control the capillary effect of the surface micro-structure, resulting in a porous structure that will extend the boiling regime and delay CHF through enhanced liquid spreading over the heated area. However, it should be noted that there is a conflict between enhanced boiling and the $\mathrm{CHF}$, because an increased number of boiling bubbles can cause an early CHF due to bubble coalescences, resultantly blocking the liquid supply.

Recently introduced nanotechnology based on new nanomaterials basically employs similar approaches as the aforementioned conventional techniques to control boiling parameters.

\section{(1)Pool Boiling and CHF}

The use of nanotechnology for surface modification can be classified into the five following classes: (a) nanorod deposition, (b) nanowires, (c) nanomaterial deposition, (d) coarse nano-/micro-structures, and (e) nanoparticle thin film coatings. Representative surface images are shown in Fig. 1.

\section{$<$ Nanorod deposition>}

Li et al [29] studied nucleate boiling focused on nanoscale gas cavities as nucleation sites are formed on $\mathrm{Cu}$ nanorods. Nanorods were deposited on a polished $\mathrm{Cu}$ substrate by an electron-beam evaporator. Through the nanosurfaces, they obtained a roughly 30 -fold increase in the density of active bubble nucleation sites, resulting in a higher boiling heat transfer coefficient. They also observed smaller bubble departure diameters and higher release frequencies related to the relatively small size of the microcavities. In addition, improved wettability, as determined by measurement of the contact angle, was acquired through the deposited surface. As the authors indicate, the most interesting point is that the improved wettability with nanorods cannot support increased nucleation sites with reduced superheat, because good wetting suppresses the bubble ebullition process to higher superheat. They claim that the interconnected network of nanopores, allowing percolation, supports the effective trapping of vapor/air and maintains the microcavity stability in order to enhance boiling activity. Therefore, they emphasize that activation of multiple scales from nano- to micro-scale plays a key role in enhancing the nucleate boiling performance of the $\mathrm{Cu}$ surface with nanorods. They also measured higher CHF values, but the increase was not outstanding. Sesen et al.[30] obtained similar results for an array of copper nanorods with average diameter of $\sim 100 \mathrm{~nm}$ and length of $\sim 500 \mathrm{~nm}$. They used a sputter deposition method to obtain the nanorods. The enhancement of the heat transfer was up to roughly five times larger than the case of planar plain surfaces.

\section{<Nanowires>}

Chen et al. [28] studied pool boiling of saturated water on nanowires comprised of $\mathrm{Si}$ or $\mathrm{Cu}$. Nanowires are vertically aligned and have diameters in a range of 20-300 $\mathrm{nm}$ for $\mathrm{Si}$ and $200 \mathrm{~nm}$ for $\mathrm{Cu}$. For both cases, the nanowires are 40-50 $\mu \mathrm{m}$ long. Both the $\mathrm{CHF}$ and boiling HTC of the nanowires are more than doubled compared

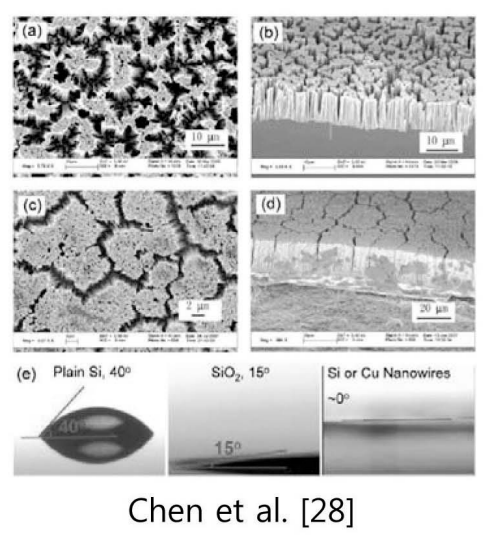

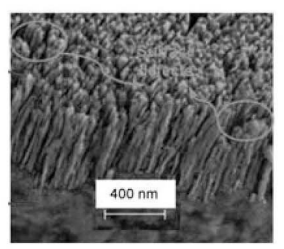

Li et al. [29]

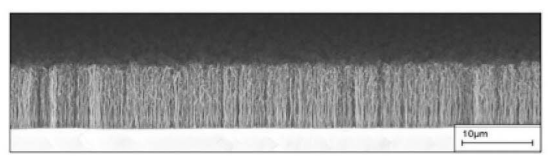

Ahn et al. [31]

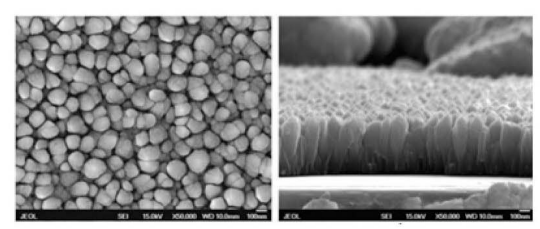

Sesen et al. [30]

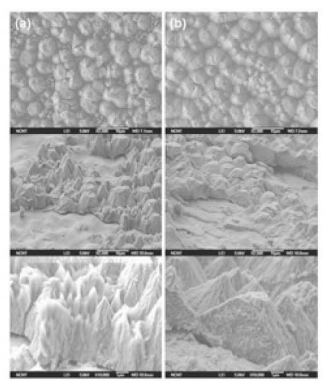

Ahn et al. [33]

Fig. 1. Nanostructures for Boiling and CHF Enhancement [28-31,33] 
to plain Si surfaces. Such enhancement can be attributed to the unique properties of nanowires, including high nucleation site density, superhydrophilicity, and enhanced capillary pumping effect.The insight obtained from this study indicates that further enhancement of the CHF and HTC is possible by rational design and synthesis of nanowire arrays. Ahn et al. [31] investigated the effects of nano-structured surfaces on pool boiling. They prepared horizontal heater surfaces coated with vertically aligned multiwalled carbon nanotubes (MWCNTs). Alignment of CNTs was accomplished using the chemical vapor deposition (CVD) process. The surface morphology of the MWCNTs was similar to that of the nanowires. They referred to this as forest-like nanostructure. They compared the BHT and CHF performance with two types of MWCNTS in terms of height. The results show that MWCNTs with $25 \mu \mathrm{m}$ height yield higher heat fluxes for both nucleate and film boiling and enhanced the CHF by $40 \%$. In the case of the MWCNTs with $9 \mu \mathrm{m}$ height, they obtained a similar BHT and $10 \%$ enhancement of CHF. They emphasized that increasing the height of the MWCNTs can extend the wall superheat, resulting in CHF enhancement. The mechanisms of BHT enhancement are based on a "pinning" effect of the liquid-vapor contact line during nucleate boiling. This alters the bubble nucleation and growth profile as well as the bubble departure frequency. In contrast, enhancement mechanisms of the $\mathrm{CHF}$ are based on formation of additional vapor due to the presence of MWCNTs on the surface and reduction of the critical Rayleigh-Taylor instability wavelength.

<Nanomaterials deposition>

Hendricks et al. [32] adopted a microreactor assited nanomaterial deposition (MAND ${ }^{\mathrm{TM}}$ ) technique to prepare nanostructured surfaces, as shown in Fig 2. They tested flower-like or carpet-like nanostructures of $\mathrm{ZnO}$ as boiling surfaces and obtained 10-fold higher boiling heat transfer and 4-fold higher critical heat flux in pool boiling.

\section{$<$ Coarse nano/micro-structures >}

Ahn et al. [33] prepared Zirconium alloy nanostructure and micro/nanostructures (so-called mountain-like structures) through an anodic oxidation process. They reported higher CHF values and lower boiling heat transfer compared to bare substrates and substrates with the microstructures. The results could be supported by improved wettability or superhydrophilicity for both trends of CHF and BHT changes.

$<$ Nanoparticle thin-film coatings>

Forrest et al. [34] studied BHT and CHF in pool boiling for nanoparticle thin-film coatings comprised of $\mathrm{PAH} / \mathrm{SiO}_{2}$ to prepare heat transfer surfaces. They obtained lower BHT and higher CHF for a hydrophilic 40 bilayer PAH/ Silica coating while a hydrophobic 20 bilayer $\mathrm{PAH} / \mathrm{SiO}_{2}$ fluorosilane coating gave higher BHT and higher CHF compared to a bare, clean surface.

They emphasized that the results could be supported by the observed change of the advancing contact angle, which is related to nucleate boiling heat transfer, and the receding contact angle, which is related to the CHF.

\section{(2)Flow boiling}

Jeon et al. [35] conducted flow boiling experiments on copper, bare silicon, and a carbon nanotube (CNT) coated silicon wafer using water. The results showed that the MWCNT coated silicon surface enables higher heat fluxes compared to the bare silicon surface. They ascribed the enhancement to the high thermal conductivity of the carbon nanotubes, a micro-layer effect, enhancement of transient heat transfer due to periodic solid-liquid contact, and an increase in active nucleation sites on the nanostructured surfaces.

\subsubsection{Fluid-modification Technology (Nanofluid technology)}

In recent years, fluids containing suspensions of nanometer-sized particles (termed nanofluids as coined by S. Choi (1995, Argonne National lab, USA: dilute liquid suspensions of nanoparticulate solids including particles, nanofibers, and nanotubes [36])) have been actively researched due to their enhanced thermal properties over the base fluids.

Traditional heat transfer fluids, such as water and refrigerants, are inherently poor heat transfer fluids due to the fundamental limit in thermal conductivity of conventional fluids. Solids have thermal conductivities that are orders of magnitude larger than those of traditional heat transfer fluids. Small solid particles (nanoparticles) of high thermal conductivity with size below $100 \mathrm{~nm}$ can suspend in aqueous solutions of surfactants or solvents without damaging the structure of heat transfer systems

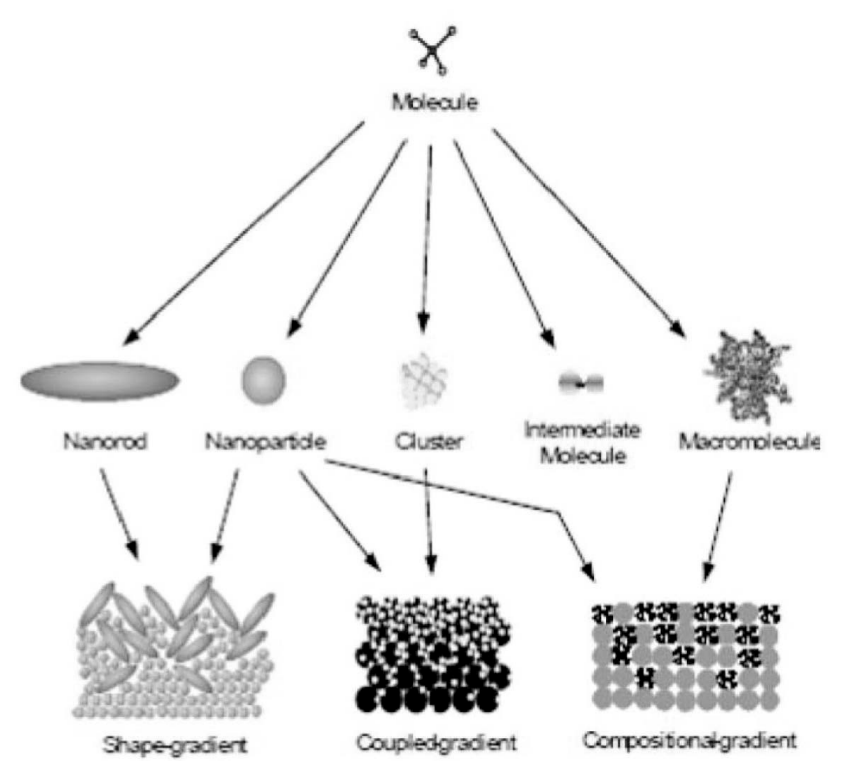

Fig. 2. Various Films of Nanostructuresby MAND ${ }^{\mathrm{TM}}$ [32] 
(i.e., there is no abrasion or clogging). Colloidal suspensions have shown intriguing thermal performances,particularly regarding the following four points: (1) increased thermal conductivity $(\sim 150 \%)$; (2) increased single-phase heat transfer coefficient $(\sim 60 \%)$; (3) increased critical heat flux with extended nucleate boiling regime ( 200\%); and (4) improved quenching efficiency. In addition, nanofluids exhibit a very significant enhancement (up to $+200 \%$ ) of the boiling Critical Heat Flux (CHF) at low nanoparticle concentration (the CHF is the limit of the most efficient heat transfer regime or nucleate boiling or the indirect limit of the above-mentioned attainable energy-source temperature) [26,77]. Owing to these factors, nanofluids are very attractive heat transfer fluids with regard to many applications. Publications on nanofluids have increased exponentially in recent years, with studies covering theoretical, experimental, and numerical aspects of formulation, characterization, flow behavior, and thermal behavior of nanofluids as innovative coolants.

Accordingly, progress can be anticipated in the development of new nanotechnology-based coolant/ engineered features that can deal with high heat loads for improving energy conversion systems such as advanced nuclear fission and fusion power plants and other nextgeneration energy systems such as solar-power and solar heating systems, computer chips, electronic devices, and man-made vehicles in terms of economics and safety.

In particular, potential nuclear safety systems adopting nanofluid coolants in current water-cooled reactors might include engineered features such as an Emergency Core Cooling System (ECCS), External Reactor Vessel Cooling System (ERVCS), and In-Vessel/Ex-Vessel Core Catcher Systems. Also, the application of nanofluids can be expanded into both PWRs and BWRs, because ABWRs also consider adopting an in-vessel retention strategy to mitigate severe accidents in the face of concerns as power capacity is raised to $\sim 1800 \mathrm{MWe}$ [77].

Many studies related to boiling and CHF have recently shown that the effects of nanoparticles in nanofluid boiling are based on deposition during boiling or evaporation of the liquid layer below bubbles. Therefore, in reality, nanofluid technology should be considered as a surface modification technology. However, fluid properties change depending on the concentration of nanoparticles in base fluids, and the effects of this cannot be ignored. In this section, we consider nanofluid technology as a fluid modification technology.

(1) Pool Boiling and CHF

The concept of utilizing in nanofluids in boiling applications related to nuclear energy was reported in 1955. Hoegerton and Grass [37] performed nucleate pool boiling heat transfer studies of systems consisting of heated platinum tubes submerged in aqueous $\mathrm{ThO}_{2}$ slurries. $\mathrm{ThO}_{2}$, a nuclear fuel material,was suspended in a liquid carrier. The results are shown in Fig.3.

However, they did not obtain improved BHT performance. The concept of nanofluids suggested in the early 1990s has been applied since the 2000s. More than 100 papers have been dedicated to nanofluid boiling heat transfer and CHF in relation to pool boiling during the past ten years. Review papers [38, 39, 40] have also been published, providing summaries of pool boiling and CHF. Many kinds of nanoparticles such as metal oxides, including $\mathrm{Al}_{2} \mathrm{O}_{3}, \mathrm{SiO}_{2}, \mathrm{TiO}_{2}$, and $\mathrm{ZnO}$, and even pure metals such as $\mathrm{Au}$ and $\mathrm{Ag}$ as well as allotropes of carbon have been investigated for boiling heat transfer (BHT) and CHF. In this paper, we focus on areas of consensus and contention regarding major performance results and mechanisms.

For boiling heat transfer, some studies have reported enhancement while most works reported deterioration or no change for boiling. Boiling heat transfer deterioration was reported in early studies on nanofluid boiling. Das et al. [41] and Bang and Chang [42] measured lower heat transfer coefficients compared to water for alumina nanofluids. You et al. [43] and Vassallo et al. [44] did not find any differences in boiling heat transfer of their nanofluids. Most studies on BHT for nanofluids yielded similar results. For boiling heat transfer enhancement, we meanwhile found only 4 papers in the literature. Wen and Ding [45] performed pool boiling heat transfer using alumina nanofluids with primary particle size of 10-50 $\mathrm{nm}$. The results showed that boiling heat transfer was enhanced by as much as roughly $40 \%$ at $1.25 \mathrm{w} \%$. However, they did not clearly account for why BHT was enhanced. Instead, they concluded that BHT is associated with the properties and behavior of the nanofluids and the boiling surface, as well as the interactions there of.

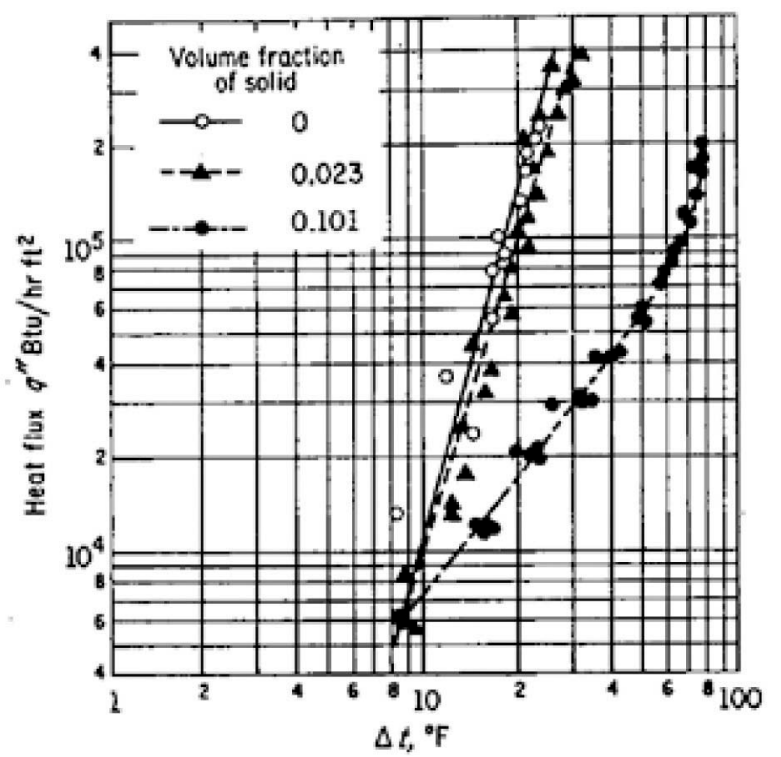

Fig. 3. Effect of $\mathrm{ThO}_{2}$-suspension Concentration on Nucleate Boiling [37] 
Park and Jung [46] carried out pool boiling experiments using R22 and water with carbon nanotubes (CNTs). The results showed that BHT was up to $27 \%$ at low heat flux such as $30 \mathrm{~kW} / \mathrm{m}^{2}$. Their experiments did not show fouling or deposition of nanoparticles. Suriyawong and Wongwises [47] investigated the effect of $\mathrm{TiO}_{2}$ nanoparticles suspended in water at less than 0.01 vol\% for copper and aluminum surfaces. The results showed that BTH values were increased by around $30 \%$ and $27 \%$ for an aluminum surface with a roughness of $0.2 \mu \mathrm{m}$ and around $27 \%$ with a roughness of $4 \mu \mathrm{m}$, respectively, while for copper surfaces, the BHT values were increased by $15 \%$ and $4 \%$ for $0.2 \mu \mathrm{m}$ roughness and $4 \mu \mathrm{m}$ roughness, respectively. While their nanofluids include dispersants or sufactants such as VP Disp. W740, leading to some additional effects, the different effects of the surface materials are interesting. Z. Liu et al [48] studied the boiling characteristics of carbon nanotube (CNT) nanofluids under sub-atmospheric pressure. The results at atmospheric pressure showed that the boiling heat transfer and the CHF increased by about $60 \%$ and $63 \%$, respectively. In addition, they reported that, at subatmospheric pressure of $7.4 \mathrm{kPa}$, both BHT and CHF increased by $130 \%$ and $200 \%$, respectively, compared with those of deionized water. They concluded that the solid-liquid contact angle or wettability was not the sole influencing factor.
The reasons for BHT enhancement in the aforementioned 4 studies are still debatable. The addition of stabilizers such as surfactants and dispersants could enhance boiling, as is well known, because surfactants can reduce the surface tension, resulting in larger bubble formations. However, it appears that surfactants were not used as stabilizers. Additional studies should thus be dedicated to this area.

One of the most interesting characteristics of nanofluids is their capability to significantly enhance the Critical Heat Flux (CHF) [43,44]. Since the CHF is the upper limit of phase-change nucleate boiling heat transfer, the most efficient heat transfer mode, such enhancement provides potential for major performance improvement in many practical applications related to thermal management. Regarding CHF enhancement, however, there remain unclear points. In particular, the level of enhancement varies widely depending on the nanofluids and research groups. This may be due to the test duration and nanoparticle morphology, which result indifferent deposition morphology and hence differences in theen hancement ratio. On the other hand, there is a consensus that such enhancement is related to buildup of a deposition layer of nanoparticles during boiling of nanofluids $[41,42,44,49,50,51]$. In order to prove this, some researchers indirectly showed that the deposition layer of nanoparticles improved both surface wettability and capillarity,as shown in Figs. 4 and 5 [50,51,26].
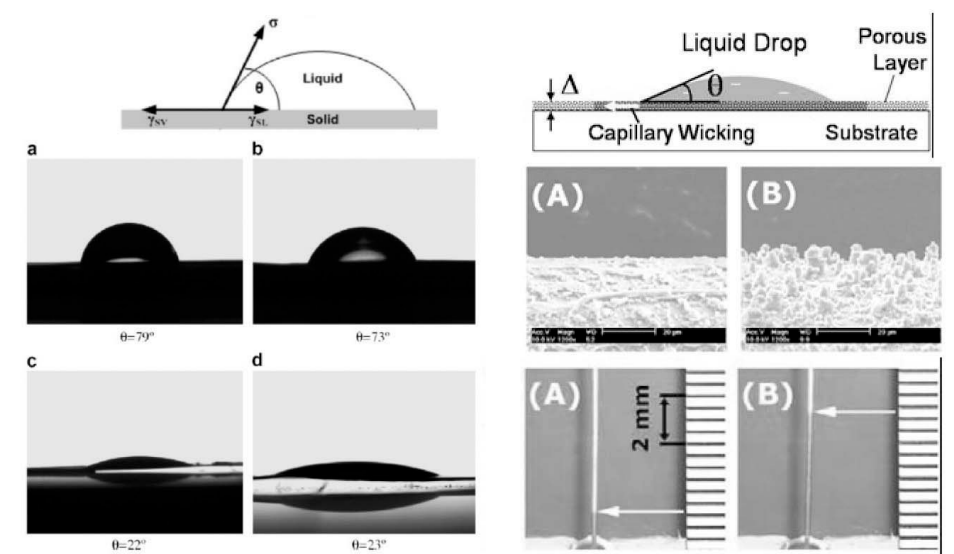

Fig. 4. Improved Wettability of Nanofluid-boiled Surface (Left) Contact Angle [50] and (Right) Capillary Wicking Height [51]

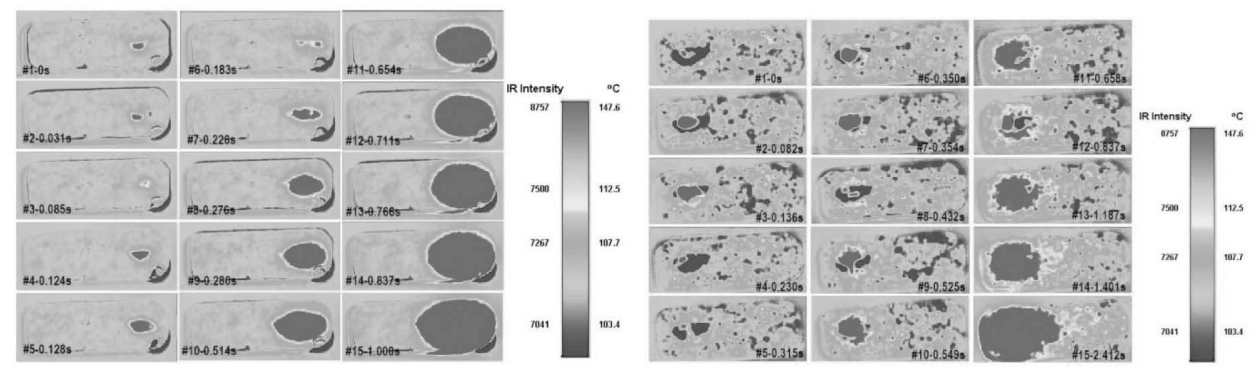

Fig. 5. Comparison of IR Images of the Heated Surface at CHF of Nanofluids, Showing Improved Wettability [26] 
Recently, Park et al [25] investigated the effects of newly-introduced graphene nanomaterials on pool boiling CHF. They surprisingly reported that there were no surface wettability improvements in terms of contact angle and even capillary action whereas maximum CHF enhancement was obtained among other tested nanofluids such as alumina. This raises a new question regarding CHF enhancement mechanisms. They argued that CHF enhancement mechanisms could be based on reduction of the Taylor instability wavelength in relation to hydrodynamic instability as Liter and Kaviany [24] and Hwang and Kaviany [52] suggested for surfaces with microporous coating. Figure 6 supports their arguments.

\section{(2)Flow Boiling and CHF}

Hoegerton and Grass [37] also performed nucleate pool boiling heat transfer studies of systems consisting of heated platinum tubes submerged in aqueous $\mathrm{ThO}_{2}$ slurries with a flow system. They obtained deteriorated BHT. Kim et al. [53] studied flow boiling CHF in nanofluids. They used a $0.01 \mathrm{v} \%$ alumina nanofluid characterized by $50 \mathrm{~nm}$ nanoparticle size. The results showed that CHF enhancement up to $\sim 30 \%$ could be achieved by the nanofluid.

Kim et al. [54] extended their flow boiling CHF studies to investigation of zinc-oxide and diamond-water nanofluids. The particles used were below $100 \mathrm{~nm}$ and at low concentration below $0.1 \mathrm{vol} \%$. The results showed that the maximum CHF enhancement was $53 \%, 53 \%$, and $38 \%$ under $2500 \mathrm{~kg} / \mathrm{m}^{2} \mathrm{~s}$ and $0.1 \mathrm{MPa}$ for alumina, zinc oxide, and diamond, respectively. They contended that the enhancement is due to improved surface wettability by the deposition of nanoparticles during boiling. Kim et al. [55] further extended their study with a focus on flow boiling heat transfer. However, the results showed that, for comparable test conditions, the values of the nanofluid and water heat transfer coefficient are similar, falling

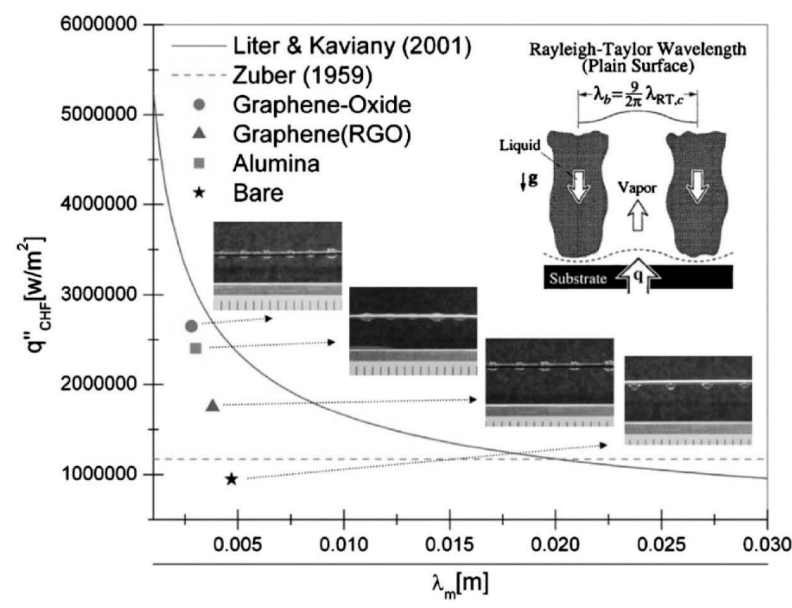

Fig. 6. Effects of a Geometrically Determined Critical Instability Wavelength [25] within 20\%. Even though they observed the deposition of nanoparticles, they did not delineate the relationship between the deposition and CHF enhancement. Bao et al. [56] experimentally investigated the subcooled flow boiling heat transfer of pre-coated test sections in water. Using a separate coating loop, stainless steel test sections were treated via flow boiling of alumina nanofluids at constant heat flux and mass flow rate. The pre-coated test sections were then used in another loop to measure the subcooled flow boiling heat transfer coefficient and CHF with water. They showed that the CHF values for the pre-coated tubing were $28 \%$ higher than that of the bare tubing at high mass flux of $\mathrm{G}=2500 \mathrm{~kg} / \mathrm{m}^{2} \mathrm{~s}$. However, they did not obtain enhancement at lower mass flux of $\mathrm{G}$ $=1500 \mathrm{~kg} / \mathrm{m}^{2} \mathrm{~s}$. They confirmed that the heat transfer coefficients did not differ much between the experiments with bare or coated tubes. They explained that the nanoparticle coating layer was not uniform and there was no relationship between the coating pattern and the amount of observed CHF enhancement.

Henderson et al. [57] performed flow boiling experiments with R-134a-based nanofluids. With direct dispersion of $\mathrm{SiO}_{2}$ nanoparticles in $\mathrm{R}-134 \mathrm{a}$, the heat transfer coefficient decreased by as much as $55 \%$ in comparison to pure R-134a. They attributed the degradation to difficulties in obtaining a stable dispersion. On the other hand, for a mixture of R-134a and polyolester oil with $\mathrm{CuO}$ nanoparticles, they found that the heat transfer coefficient increased by more than $100 \%$ over the baseline R-134a/polyolester results. Ahn et al. [58] investigated flow boiling of a nanofluid on a short heated surface. They used an alumina nanofluid at aconcentration of $0.01 \mathrm{v} \%$. The results showed that the CHF was enhanced by $24 \%$ at $1 \mathrm{~m} / \mathrm{s}$ and $40 \%$ at $4 \mathrm{~m} / \mathrm{s}$. They explained that the improved surface wettability due to nanoparticle deposition caused the CHF enhancement. Kim et al. [59] performed flow boiling CHF experiments using an alumina nanofluid and an alumina nanoparticle deposited tube. They showed that the flow boiling CHF of the $\mathrm{Al}_{2} \mathrm{O}_{3}$ nanofluid with a plain tube (NFPT) and deionized water with an $\mathrm{Al}_{2} \mathrm{O}_{3}$ nanoparticle deposited tube (DWNT) were enhanced by up to about $80 \%$. They also found that there was not a major difference in the CHF results between NFPT and DWNT. They thus insisted that these results indicate that the CHF enhancement of the $\mathrm{Al}_{2} \mathrm{O}_{3}$ nanofluid is caused by deposition of nanoparticles on the inner surface of the test section tube. Vafaei and Wen [60] investigated flow boiling of alumina nanofluids in $510 \mu \mathrm{m}$ single microchannels with a focus on the effect of nanoparticles on the critical heat flux. The results showed that $\sim 51 \%$ CHF enhancement was obtained under $0.1 \mathrm{vol} \%$. They also emphasized that nanoparticle deposition and subsequent modification of the boiling surface are responsible for the different boiling behaviors. Vafaei and Wen [61] noted additional potential mechanisms underlying the effects of nanofluids on flow boilng heat 
transfer. They argued that nanoparticles play dual roles, i.e., (i) modification of the heating surface through particle deposition, and (ii) modification of bubble dynamics through particles suspended in the liquid phases.

Ahn et al. [62] studied the effects of nanoparticle surface deposition on flow boiling CHF from a short heated wall through visualization. Through a heater precoated with nanoparticles, they observed that the wetting zone fraction near the $\mathrm{CHF}$ was larger than that of a bare heater. They contended that $\mathrm{CHF}$ enhancement of the nanoparticle-coated heater is related to enhanced surface wettability based on capillary action. They concluded that it also could be related to a representative $\mathrm{CHF}$ model of the liquid sublayer. Lee et al. [63] performed flow boiling experiments to investigate the effects of alumina nanofluid on the CHF. The nanoparticles had a cylindrical shape with diameters below $50 \mathrm{~nm}$. The results showed that $\mathrm{CHF}$ enhancement is proportional to mass flux, resulting in $\sim 40 \%$ enhancement at $500 \mathrm{~kg} / \mathrm{m}^{2} \mathrm{~s}$. The $\mathrm{CHF}$ enhancement was ascribed to enhanced wettability.

\section{(3) Quenching}

Quenching phenomena based on rapid cooling of a liquid on a hot surface are characterized by boiling phenomena. In particular, when a loss of coolant accident occurs in NPPs, the fuel can reach very high temperatures, threatening the integrity of the fuel and cladding. The emergency core cooling system (ECCS), which injects water into the reactor core, immediately starts to work to decrease the fuel temperature [67-69]. Cooling starts with developing a quench front as the head of liquid advances along with the fuel element. The speed of the quench front, and thus the peak fuel temperature reached during the accident, depends on a combination of factors including nucleate boiling, film boiling, and wetting condition of the fuel surface. It could be assumed that the use of nanofluids potentially could improve the quench front speed and thus enhance the safety of the reactors. [67-69] In fact, the quenching front is governed by the boiling phenomena. Some studies have focused on the effects of nanofluids on quenching.

Park et al. [64] carried out quenching experiments with a copper sphere in alumina nanofluids. The concentration of nanoparticles ranged from 5 to $20 \mathrm{vol} \%$. The results showed that the film boiling heat transfer coefficient in the nanofluids was lower than that in pure water. They used a pre-quenched sphere in nanofluids and thereupon obtained much more rapid quenching compared to a clean sphere. They explained that nanoparticle deposition on the previously-quenched sphere (similar to a coating technique) prevents the formation of a stable vapor film on the sphere surface, with the result that the film boiling regime is bypassed. Xue et al. [65] performed quenching experiments with a nickel-plated copper sphere in a pool of water-based nanofluids containing carbon nanotubes (CNTs). They also found that, as compared to water, an aqueous gum arabic solution has an enhanced critical heat flux, transition boiling, and minimum heat flux point in film boiling as the Leidenfrost point. CNT nanofluids have a higher CHF than GA solutions. The CNTs are deposited on the surface during quenching. Lotfi and Shafii [66] investigated the BHT characteristics of nanofluids through transient quenching experiments with a high temperature silver sphere in water-based nanofluids with $\mathrm{Ag}$ and $\mathrm{TiO}_{2}$ nanoparticles. A silver sphere with a diameter of $10 \mathrm{~mm}$ and an initial temperature of $700{ }^{\circ} \mathrm{C}$ was quenched in nanofluids at a temperature of $90^{\circ} \mathrm{C}$. The results showed that nanoparticle deposition on the sphere surface resulted in rapid quenching of the hot sphere while the nanofluid itself could not provide good quenching to a clean sphere. Bang [67] studied the effect of $\mathrm{SiC}$ nanoparticles on the quenching heat transfer for an Inconel 600 cylindrical rod of $12.5 \mathrm{~mm}$ diameter and $60 \mathrm{~mm}$ length, as shown in Fig. 7. The maximum cooling rate in nanofluids was found to be marginally higher $(\sim 6 \%)$ than that in pure water.

Kim et al [68] studied the effects of nanofluids and nanoparticle deposition on quenching in water-based nanofluids with alumina, silica, and diamond nanoparticles using small $(\sim 1 \mathrm{~cm})$ metallic spheres. The results showed that the quenching behavior in nanofluids is almost similar to that in pure water, with the result that the effect of the nanofluid is negligible for the quenching performance.
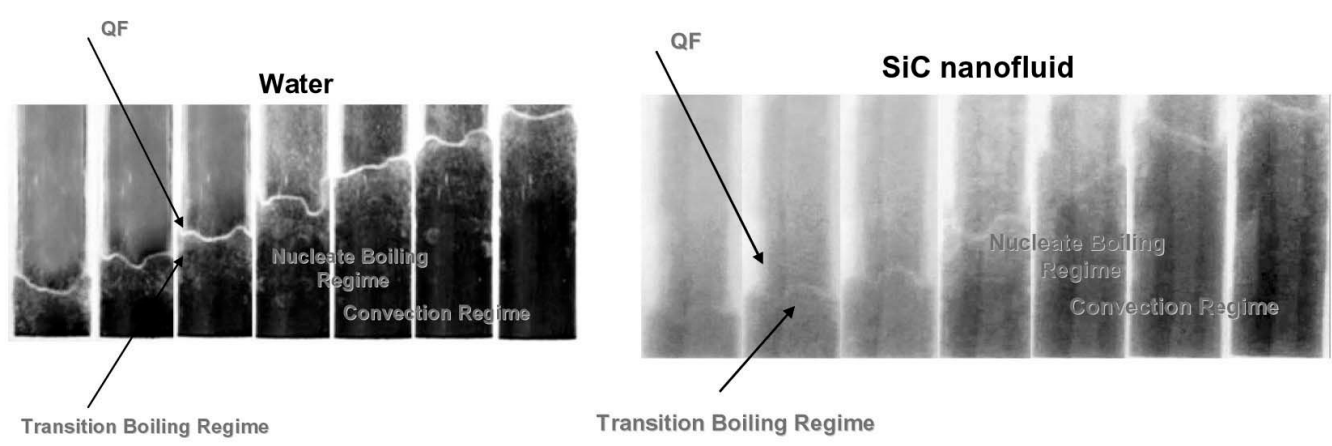

Fig. 7. Nucleate Boiling and Propagation of Quench Front $(\sim 9 \mathrm{~mm} / \mathrm{sec})$ [67] 
Kim et al. [69] investigated the quenching characteristics of metallic rodlets and spheres in pure water and waterbased nanofluids with alumina nanoparticles of $0.1 \%$ by volume. The results demonstrate that while the initial quenching behavior in nanofluids is similar to that in pure water, both the minimum heat flux and quench front speed are largely increased in a subsequent quenching series due to nanoparticle deposition (similar to a coating technique). They explained that the liquid-solid interaction during such short-lived contact is more vigorous when a nanoparticle layer with improved surface wettability, which leads to premature disruption of film boiling and quenching acceleration, as shown in Fig. 8 .

Chun et al. [70] investigated the effects of nanofluids on boiling heat transfer during rapid quenching of a thin platinum $(\mathrm{Pt})$ wire. Typical overall boiling curves were obtained from the cooling curves of the Pt wire for water, silicon ( $\mathrm{Si}$ ), and silicon carbide ( $\mathrm{SiC}$ ) nanofluids. They showed that meaningful differences in the behavior of the boiling curves between the water and the nanofluids cannot be identified during quenching. However, when the $\mathrm{Si}$ and $\mathrm{SiC}$ nanoparticle-coated $\mathrm{Pt}$ wires were quenched with water, a very high cooling rate is observed and a very different boiling curve from that of water and nanofluids appeared. Bolukbasi and Ciloglu[71] studied the pool boiling heat transfer characteristics of a vertical cylinder (20 mm diameter and $75 \mathrm{~mm}$ length) quenched by $\mathrm{SiO}_{2}$-water nanofluids. As a coolant, pure water and $\mathrm{SiO}_{2}$-water nanofluid suspensions at four different concentrations $(0.001,0.01,0.05$, and $0.1 \mathrm{vol} . \%)$ were used. The results showed that the pool film boiling heat transfer in nanofluids is identical to that in pure water. However,during repeated tests in nanofluids with high

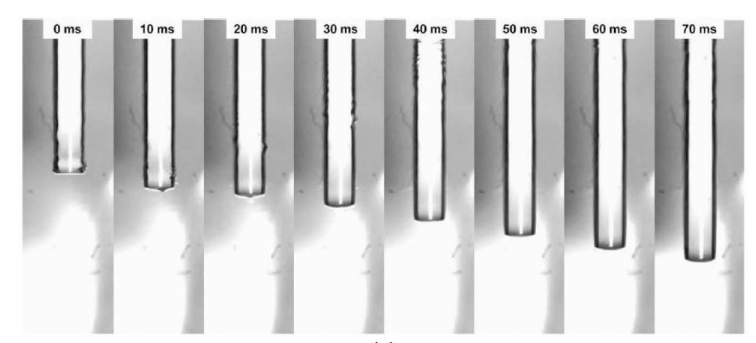

(a)

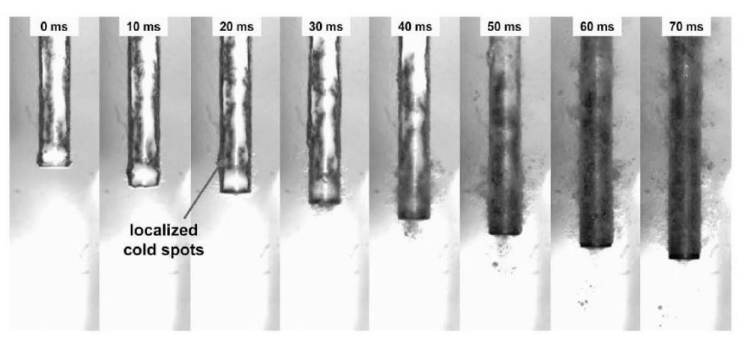

(b)

Fig. 8. Film Boiling and Quenching Phenomena [68] concentrations, the film boiling region disappears, and the critical heat flux increases. In addition, they observed that the nucleate pool boiling heat transfer coefficient decreases compared with that of pure water, but a considerable decrease in nucleate pool boiling heat transfer is not observed with repeated tests. They explained that a change in the surface characteristics due to the deposition of nanoparticles on the surface has a major effect on the quenching process. Cilonglu and Boulukbasi [72] extended their previous work [71] to $\mathrm{Al}_{2} \mathrm{O}_{3}, \mathrm{TiO}_{2}$, and $\mathrm{CuO}$ nanoparticle-dispersed nanofluids. They obtained similar results indicating that there were no direct effects of nanoparticles, but repeated quenching showed improved performance due to the deposition of nanoparticles.

(4) Nanofluid-engineered Nuclear Coolants and Safety Features

Nanofluid studies related to CHF enhancement indicate that the use of nanofluids as a nuclear coolant in the primary cooling loop of a light water reactor could improve heat removal from the core in terms of higher DNBR (Departure from Nucleate Boiling Ratio). In addition, CHF enhancement provides a larger safety margin into External Reactor Vessel Cooling for InVessel Retention as a severe accident management strategy [73-74]. Recently, Hadad et al. [75] studied the nuclear effects of various nanofluids for theVVER-1000 reactor core. The results showed that, for normal operation, where a minor change of $\mathrm{K}_{\text {eff }}$ is tolerated, $\mathrm{Al}_{2} \mathrm{O}_{3} /$ water is a better nanofluid. However, in transient and accident conditions where retention is the purpose of nanofluid use, $\mathrm{Cu} /$ water and $\mathrm{ZrO}_{2}$ nanofluids will depress $\mathrm{K}_{\text {eff }}$ most. In addition, they showed that $\mathrm{k}_{\text {eff }}$ is decreased with increasing thickness of the nanoparticle deposition layer on the fuel cladding. Figure 9 supports their results while Fig. 10 shows the change of the local power peaking factor.

Buongiorno et al. [76] assessed the feasibility of using nanofluids to enhance the in-vessel retention capability in light water reactors. They first assessed the benefits of CHF enhancement by nanofluids for decay heat power removal.

They also suggested a conceptual nanofluid injection safety system, as shown in Fig.11 and evaluated the diffusion phenomena of injected nanofluids in ex-vessel cooling channel, as shown in Fig. 12.

Bang et al. [77] studied the feasibility of nanofluidengineered ECCS. They emphasized the independence of the nanofluid injection tank based on comparison with other existing safety features such as SIT and SIP and SCS through axiomatic design work, as shown in Fig. 13. They also provided guidelines for the timing of delivery of the nanofluid to prevent core meltdown in a LOCA.

Kang et al. [78] suggested a nanofluid-engineered SIT specifically established to meet the design requirements of a safety injection system, as shown in Fig 14. 

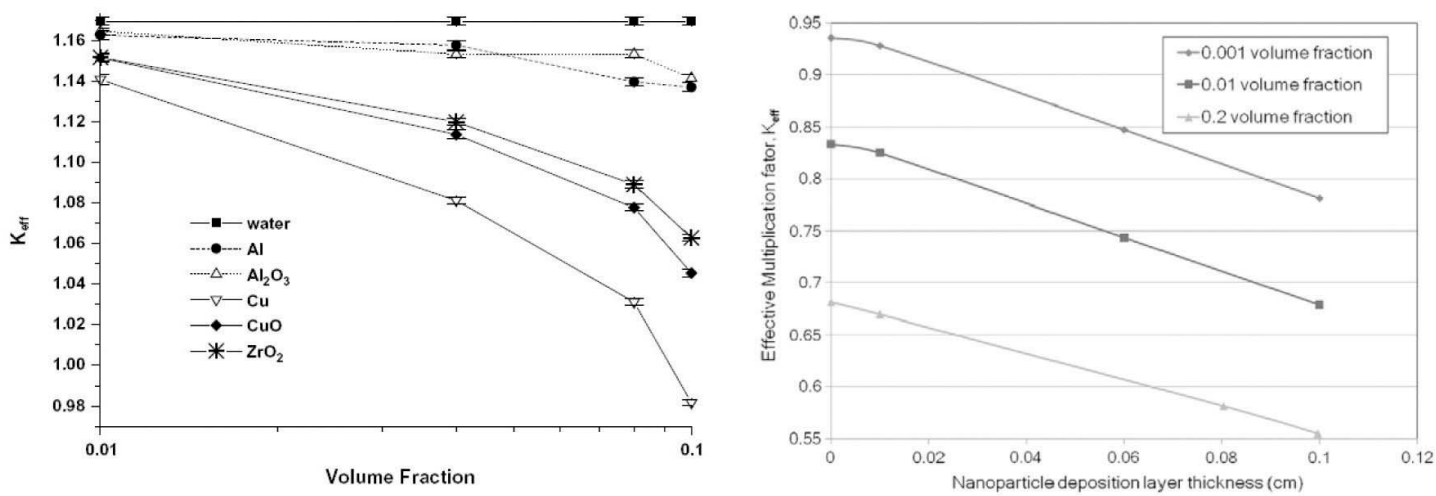

Fig. 9. Effective Multiplication Factors of Core for Different Types of Nanoparticles with Different Volume Fractions and the Effect of $\mathrm{Al}_{2} \mathrm{O}_{3}$ Nanoparticle Deposition Layer on $\mathrm{K}_{\text {eff }}$ with Different Nanofluid Volume Fractions [75]
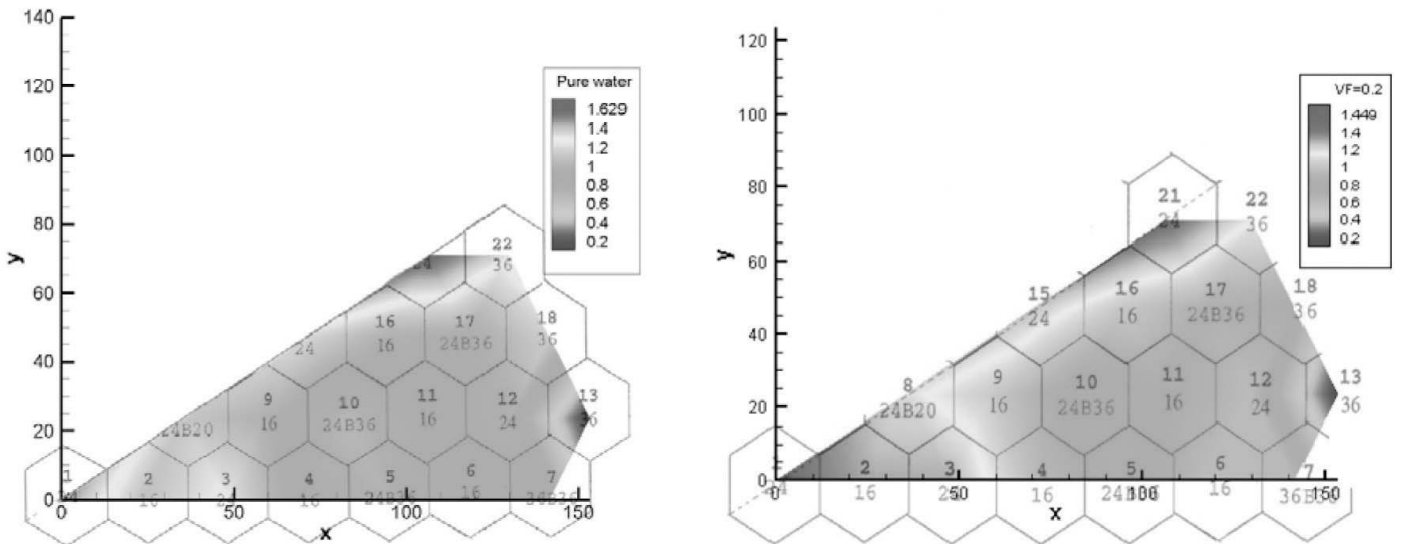

Fig. 10. LPPF(Local Power Peaking Factor) Maps for Pure Water and $\mathrm{Al}_{2} \mathrm{O}_{3} /$ Water Nanofluids $(0.2$ vol\%) [75]

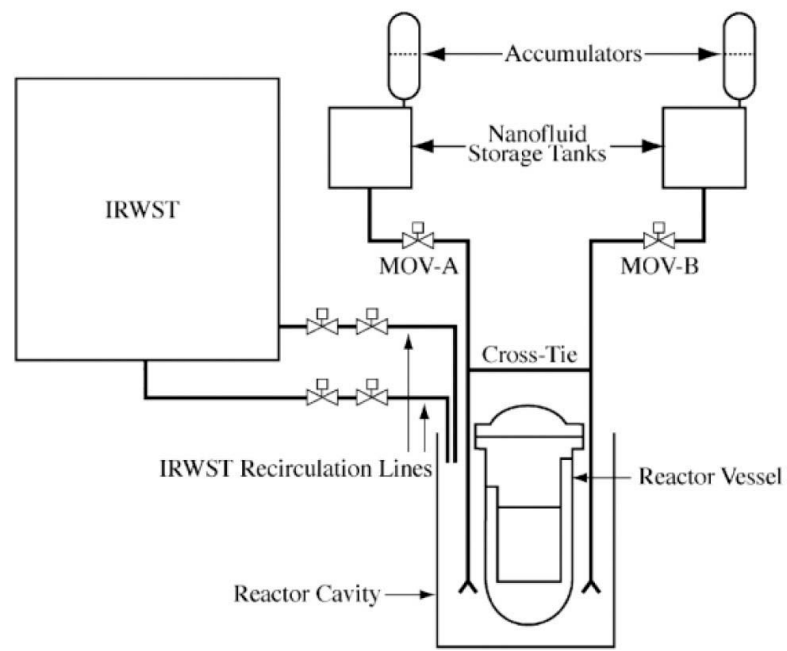

Fig. 11. Nanofluid Injection System for IVR-ERVC [76]

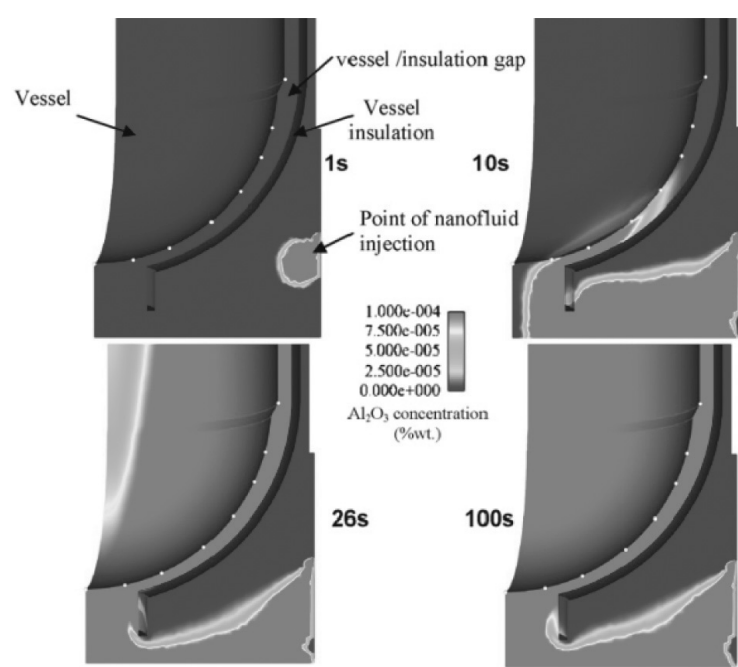

Fig. 12. Diffusion of Nanofluids to Ex-vessel Cooling Channel.[76] 


\begin{tabular}{c|c|c|c|c}
\hline & SIT-Advanced & SIP & NIS & SCS \\
\hline & $\mathrm{x}=11$ & $\mathrm{x}=12$ & $\mathrm{x}=2$ & $\mathrm{x}=3$ \\
\hline DPx1 & Tanks & IRWST & Tanks & SCHx \\
\hline DPx2 & Pressurized nitrogen & SIPs & Pressurized nitrogen & SCPs \\
\hline DPx3 & Passive actuation & Automatic actuation & Passive actuation & Manual actuation \\
\hline DPx4 & Valve arrangement & Valve arrangement & Valve arrangement & Valve arrangement \\
\hline
\end{tabular}

Fig. 13. Comparison of Design Parameters and Independence of Safety Systems and Nanofluid Injection System [77]

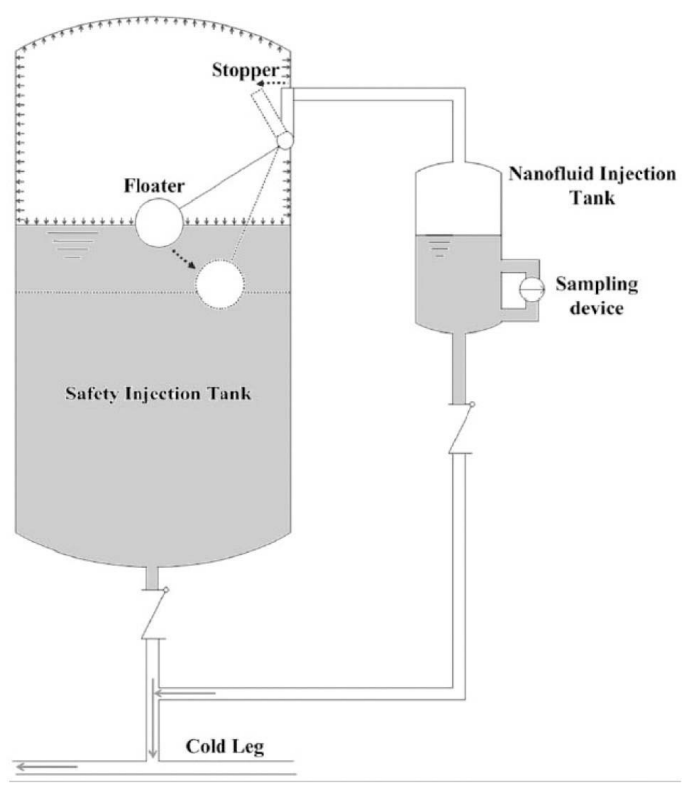

Fig. 14. Nanofluid-engineered SIT [78]

\subsection{Advancements of Condensation Systems \\ 3.2.1 Condensation Modes}

Condensation can be classified into several categories depending on the phase contact structure and condensate behavior.

Condensation $\left\{\begin{array}{l}\text { direct condensation } \\ \text { indirect condensation } \\ \text { homogeneous condensation }\end{array}\left\{\begin{array}{l}\text { film - wise condensation (FWC) } \\ \text { drop - wise condensation (DWC) }\end{array}\right.\right.$

Direct-contact condensation refers to condensation of vapor that is in direct contact with a subcooled liquid; for instance, condensation of vapor bubbles in a subcooled liquid or condensation on liquid droplets entrained in the vapor. Direct contact condensation is utilized in the SDS and CSS of NPPs. In an abnormal situation, the high pressure steam of a pressurizer may be bled to sparger pipes submerged in the RWST water pool. Steam jets coming out of the sparger holes come into direct contact with subcooled water and condense. CSS also utilizes direct contact condensation. Water droplets sprayed by the CSS will come into direct contact with steam in the containment atmosphere and condense the steam.

If vapor cools down below its saturation temperature or expands to reduce pressure below its saturation pressure, condensation can occur in the vapor bulk. This mode of condensation is called homogeneous condensation and is facilitated by foreign particles such as dust. Dew, fog, mist, and clouds, are the result of this homogeneous condensation phenomenon in the atmosphere. This condensation mode is found in steam turbines of NPPs. During expansion of steam in steam turbines, steam pressure reduces below the saturation pressure and nucleation of droplets starts spontaneously in the bulk of steam. The water droplets entrained in the steam flow cause erosion of the turbine blades and thermodynamics as well as aerodynamic losses in steam turbines.

In many applications, vapor is separated from the cooling medium by a wall, since the working fluid (vapor) should not be mixed with the cooling medium such as seawater or atmospheric air. In this case, vapor is not in direct contact with the cooling medium but in contact with the wall so as to reject thermal energy. Condensation occurs on the wall surface when the surface temperature is below the saturation temperature of adjacent vapor. Initially, water droplets nucleate on the cold wall. As the condensation proceeds, these droplets grow and may start rolling down the wall to reproduce a fresh dry surface. Or, these droplets may coalesce to form a condensate film on the wall surface and flow downward as a result of gravity. The former type of condensation is termed dropwise condensation (DWC) while the latter is known as filmwise condensation (FWC). DWC is observed on hydrophobic surfaces where the contact angle is much larger than 90 degrees while FWC occurs on hydrophilic surfaces where the contact angle is smaller than 90 degrees.

It should be noted that condensation on a conventional non-treated surface does not show pure FWC nor DWC but instead displays a somewhat mixed mode. Fig. 15 shows visual observations of FWC, DWC, and mixed 


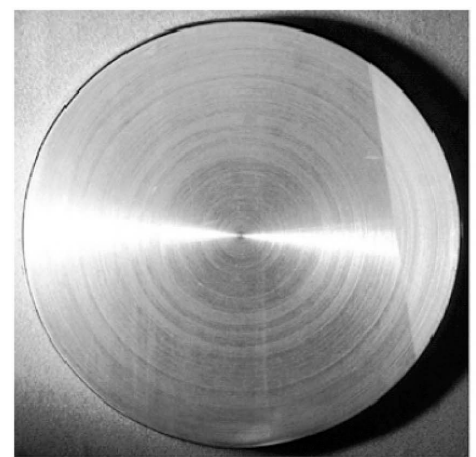

(a)

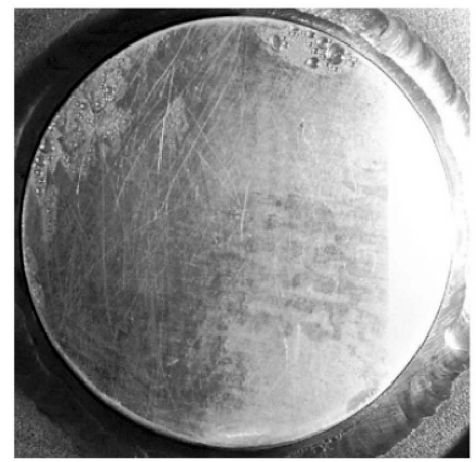

(c)

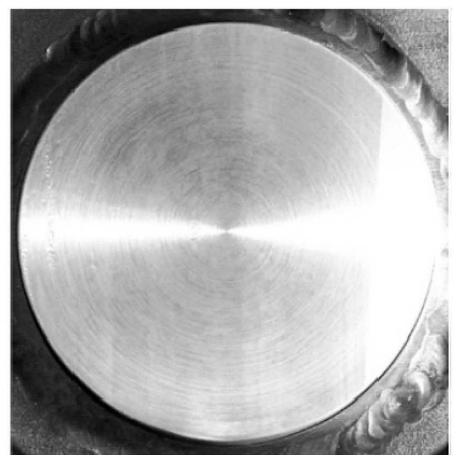

(b)

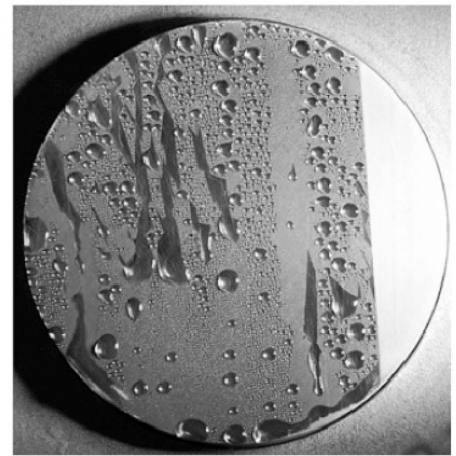

(d)

Fig. 15. FWC on Unpolished Al 3003 (a) and on Unpolished Al 6951 (b), Mixed FWC/DWC on the Implanted Part of Polished Al 3003 (c) and DWC on the Implanted Part of Polished Al 6951 (d); all Samples Treated with Ion Selective Ion Beam Implantation Technology [83]

condensation. The condensate on a conventional nontreated surface usually tends to adhere to the surface and form large liquid drops. If these liquid drops are large in diameter, they will work as thermal resistance, resulting in poor condensation heat transfer. For this reason, engineers need to find a way to reduce the condensate thickness.

FWC as well as DWC are recommended in this regard. When FWC occurs, large bumpy liquid drops spread to form a thin liquid film on a cold surface such that the average condensate thickness is minimized. Owing to this reduced condensate thickness or thermal resistance, the condensation heat transfer coefficient with FWC is larger than that for conventional condensation on a nontreated wall. Theoretical analyses were well developed by Nusselt [79]. Most engineering components where condensation is intended to occur are designed to facilitate FWC, as it is not easy to maintain the surface characteristics for long period to facilitate DWC. On the other hand, when DWC occurs, due to gravity, a liquid drop only grows to a size that will roll down the surface. As it rolls down, it wipes the surface in its path so that fresh dry surface is exposed to the vapor, where thermal resistance is minimized. Hence, the condensation heat transfer coefficient with
DWC mode is one order of magnitude larger than that for FWC. That is, DWC is speculated to be the most effective condensation process. For instance, DWC was reported to be up to 30 times more effective than FWC when tested with Langmuir-Blodgett treated surfaces [80, 81], and 5 20 times better when a DWC promotion surface is used [82]. These previous works imply that the performance of a heat rejection system will be improved and the system size can be reduced if DWC is facilitated with the system. Therefore, DWC has strong potential to impact nuclear power plant performance and safety.

\subsubsection{Hydrophobic Surfaces}

(1)Hydrophobic surfaces

Hydrophobic surfaces are found in nature. For instance, the super-hydrophobic nature of lotus leaves is a representative example considered in biomimetics. Lotus leaves repel rain drops on their uniformly superhydrophobic surface with the result that water droplets roll off of the leaves [84]. Some beetles dwelling in the Namib Desert, one of the most arid areas in the world, have developed a unique technique to survive in this dry environment. They collect drinking water from early 
morning fog-laden wind on their backs. Small water droplets form by virtue of the insect's bumpy surface, which consists of alternating hydrophobic, wax-coated and hydrophilic, non-waxy regions [85]. More than twohundred plants and many insects exploit hydrophobic characteristic to protect themselves against water. The morphology of plant surfaces has been studied comprehensively by Neinhuis and Barthlott [86] and Callies and Quere [87]. Characteristics of hydrophobic surfaces were first scientifically investigated a century ago. Boys [88], for example, noticed that water deposited on a layer of lycopodium rolls into perfect, small spheres. Since then, there have been several reviews on the wetting properties of surfaces, as they are of great interest to scientists in physics as well as in biology [89, 90, 91]. However, this area of study attracted much greater attention in the late 1990s thanks to two achievements. The first was a systematic study of the water repellency of plants reported by Barthlott and Neinhuis [92]. They emphasized the role of micro-textures on the surfaces of leaves to promote such an effect. Fig. 16 shows the lotus leaf's unusual surface topography, featuring micrometerscale protuberances with nanometer-sized hair-like fine structures. The second was the manufacture of hydrophobic textured surfaces with contact angles reportedly as high as $174^{\circ}[87,93,94,95]$. For instance, Fig. 17 shows a twotier texture mimicking the surface of lotus leaves, which was fabricated by depositing carbon nanotubes (CNTs) on micromachined pillars.

Hydrophobic surfaces have large potential in a wide range of applications. For instance, a self-cleaning characteristic might help remove dust on high-rise building walls and passenger cars. Low surface energy may help reduce frictional head loss of a body moving through water. In addition, hydrophobic surfaces enhance the condensing heat transfer coefficient, and thus may find various potential applications in NPP design.

(2)Hydrophobic surface modeling

Molecules on a liquid drop surface have fewer bonds with neighboring molecules and consequently have higher energy than molecules in the interior. This additional energy is characterized quantitatively by surface tension or surface free energy, $\gamma$, which is equal to the work that is required to create a unit area of the surface at a constant pressure and temperature. This energy can be read as the energy per unit surface area or as the tension force per unit length of a line at the surface. If a liquid drop is placed on a flat solid surface, as illustrated in Fig. 18, the liquid and solid surfaces will maintain equilibrium at a characteristic angle called the static contact angle, $\theta$. This
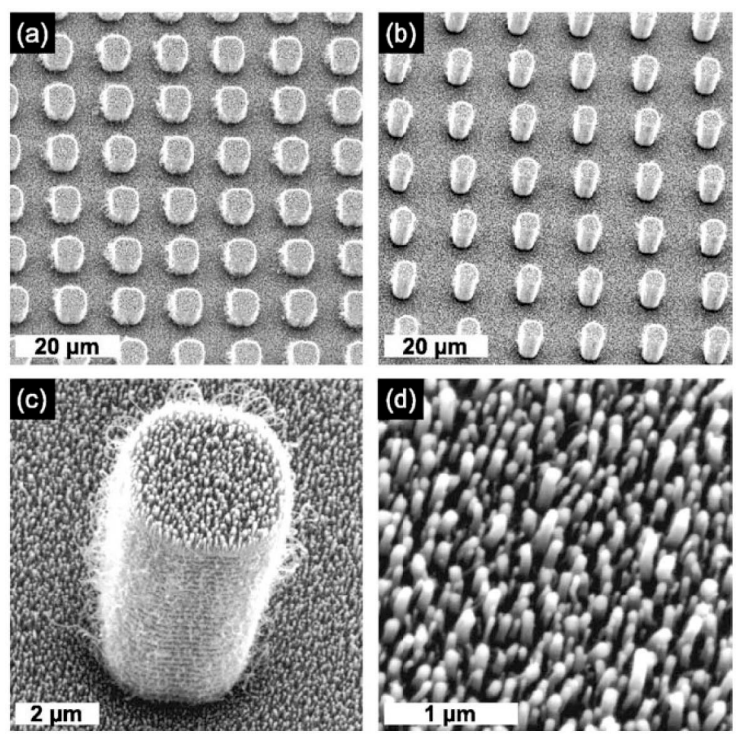

Fig. 17. Two-tier Textures: Micropillars are Etched in Silicon and CNT Nanopillars are Subsequently Deposited [95]

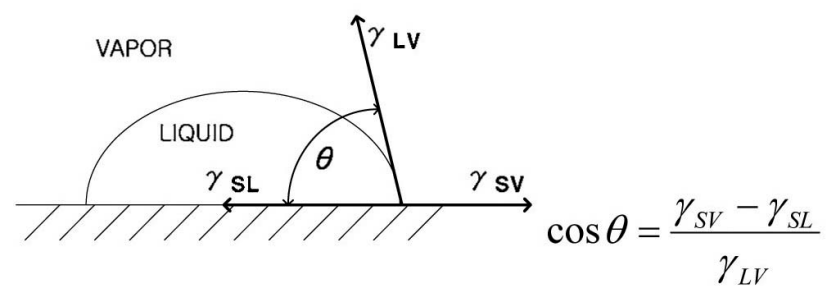

Fig. 18. A Liquid Drop on a Flat Surface and its Contact Angle
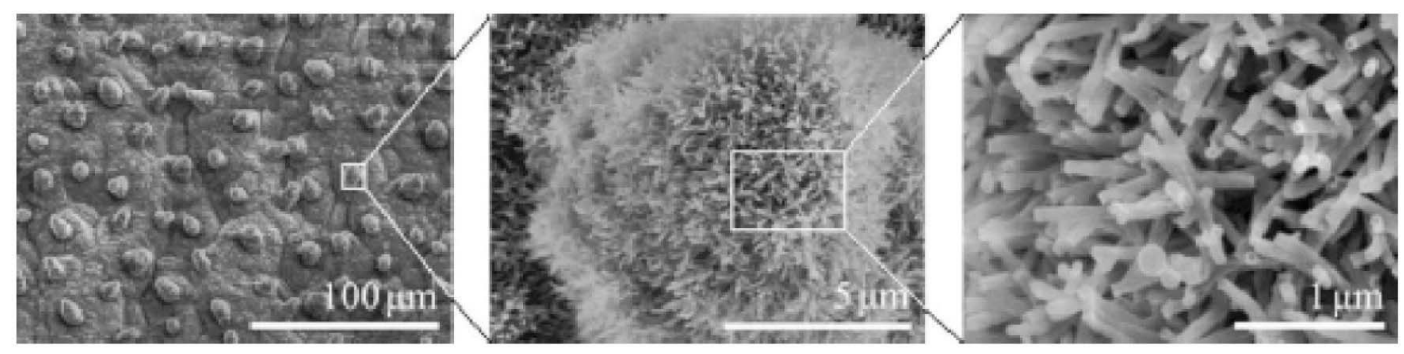

Fig. 16. FE-SEM Images of the Surface Structures of a Rosa Plena Lotus Leaf [96] 
contact angle is determined by minimizing the net surface free energy of the system [97], and the wellknown Young's equation is then obtained [98]. Where $\gamma_{S V}$ and $\gamma_{S L}$ are the surface energies of the solid against air and liquid, and $\gamma_{L V}$ is the surface energy of the liquid against air. This equation provides an expression for the static contact angle for given surface energies.

Young's equation is not applicable to a rough surface. Liquid drops situated on a rough surface are mainly observed in two different states, Cassie-Baxter and Wenzel state. A drop in a Cassie-Baxter state is just suspended on the asperities of the underlying surface, leaving air below (Fig. 19(a)). The Wenzel state is, instead, characterized by complete contact between the drop and the substrate (Fig. 19(b)). Physics concerning a solid surface on which a gas and liquid are in contact have attracted interest since the 1930s for hydrophobic fiber development. The first model was suggested by Wenzel [99, 100]. He assumed that the liquid drop is in complete contact with a rough surface and suggested the following equation:( $\theta$ : contact angle of a flat surface; $\theta^{*}$ : apparent contact angle; $r$ : roughness factor, the ratio of the actual contact area to the apparent contact area)

$$
\cos \theta^{*}=\frac{r\left(\gamma_{S V}-\gamma_{S L}\right)}{\gamma_{L V}}=r \cos \theta
$$

The principle describing the relationship between water repellency and surface roughness was suggested by Cassie and Baxter [101]. They extended Wenzel's equation for a composite interface to develop the following relationship.

$$
\cos \theta^{*}=\frac{\phi_{s}\left(\gamma_{S V}-\gamma_{S L}\right)}{\gamma_{L V}}-\left(1-\phi_{s}\right)=\phi_{s}(\cos \theta+1)-1
$$

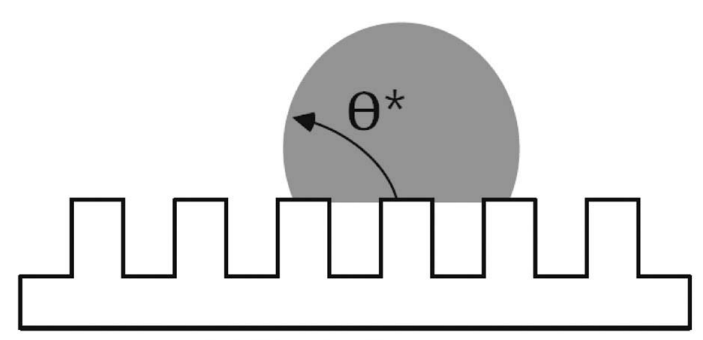

(a) Cassie-Baxter state

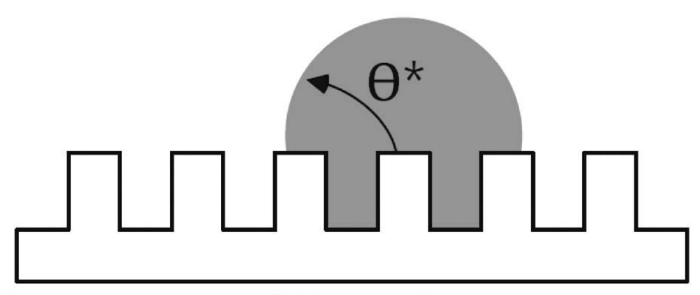

(b) Wenzel state

Fig. 19. Two Wettability States[87] where $\phi_{\mathrm{s}}$ represents the ratio of the actual contact area to the total apparent area.

Physical models for condensate nucleation and its growth are required to evaluate DWC. The Kelvin equation can be used to estimate the initial droplet diameter at the equilibrium state [102]. This equation relates the equilibrium vapor pressure at the interface between liquid and vapor phases.

$$
\ln \frac{p}{p_{o}}=\frac{2 \gamma V_{m} \cos \theta}{r_{\min } R T}
$$

where $p, p_{o}, V_{m}, R, r, T$ represent the actual vapor pressure, saturated vapor pressure, molar volume, universal gas constant, droplet radius, and temperature, respectively. Rose and Glicksman[103] derived a relationship for the growth rate of a liquid drop on a hydrophobic coated surface based on Le Fevre and Rose's equation [104] for the average heat flux for a drop surface. They related conductive heat transfer through the solid/liquid contact area and convective heat transfer through the liquid/vapor interface and suggested the following equation:

$$
\frac{d r}{d t}=\frac{2 \Delta T \cdot k_{c} \cdot h_{i}\left(1-\cos ^{2} \theta\right)}{\rho H_{f g}\left\{r \cdot h_{i}(1-\cos \theta)+2 k_{c}\left(1-\cos ^{2} \theta\right)\right\}}
$$

where $\Delta T, k_{c}, h_{i}, H_{f g}$, and $\theta$ represent the temperature difference between the substrate and vapor, thermal conductivity of the condensate, the interfacial heat transfer coefficient, latent heat of vaporization, and contact angle. This equation implies that the contact angle and radius of a droplet are also influential to the droplet growth rate.

The equations introduced above concern condensate drop behavior on a flat surface. Even though there has been advancement since the above equations were first suggested, there have not been significant breakthroughs. Modeling relevant to DWC on rough surfaces or textured surfaces is even less developed. In order to estimate DWC performance on textured surfaces, dynamic models rather than static models are required. Considering visual observations in recent works, DWC on a hydrophobic textured surface takes place as illustrated in Fig. 20. Condensate droplets may nucleate somewhere in the valley or vertical wall of a structure or on top of the structure. The condensate droplets will grow and coalesce to fill the valley of the structure and cover the top of the structure to achieve a Wenzel state. If the water in the valley can be lifted up to change its state to the Cassie state, the condensate droplets will lose some contact area and readily roll down the surface. In order to achieve better understanding of the mechanism and theory concerning dropwise condensation on hydrophobic textured surfaces, sound physical models to answer the following questions are needed:

a. How and where does a condensate droplet nucleate on a textured surface? 


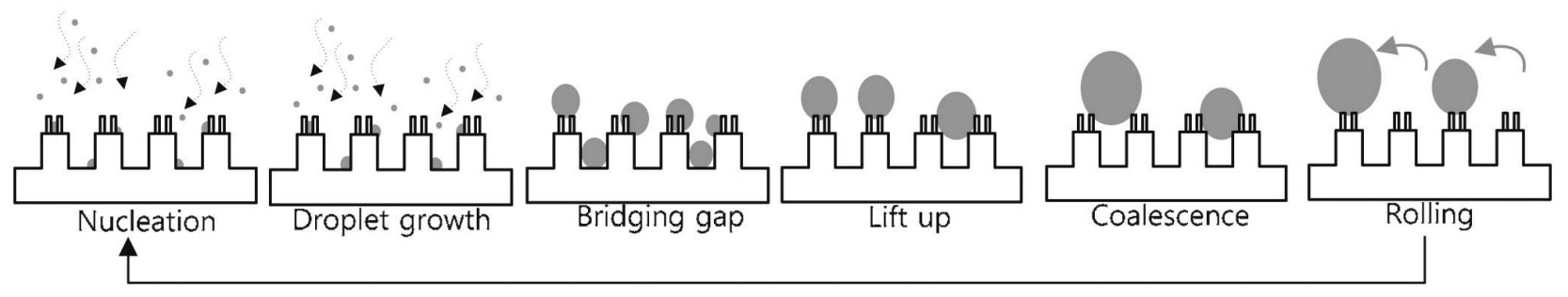

Fig. 20. Conceptual Illustration of DWC on a Superhydrophobic Textured Surface

b. How do adjacent droplets coalesce?

c. How is a liquid droplet grown in the valley of a textured surface lifted up?

d. When does a water droplet start to roll down a textured surface?

Furthermore, there is still debate concerning the mechanism of dropwise condensation. Liquid droplets have been assumed to nucleate on a dry surface in dropwise condensation modeling. On the contrary, Song et al. used thin film measurement technology to examine the condensing surface and claimed that a thin film of condensate exists on the area among the droplets and a film of condensate also exists at the locations from which the droplets departed [105]. In addition, some experimental and theoretical investigations have been made concerning the transition from dropwise condensation to filmwise condensation. This subject was reviewed and well addressed by J.W. Rose [106].

\subsubsection{DWC on Treated Surface}

Dropwise condensation takes place on a solid surface whose surface energy is relatively small. Hence, dropwise condensation could be promoted by modifying the surface of a solid substrate such that it has lower surface energy. For instance, physical or chemical coatings or ionimplantation technologies can be used to create a lowfree-energy surface. Up to the 1990s, numerous dropwise condensation studies were conducted with a thin layer of a metal-organic compound or low-surface-fee-energy polymer coated flat surfaces. [80, 107, 108, 109]. For instance, Marto et al. [107] examined several polymer coatings in terms of their ability to promote and sustain dropwise condensation of steam. They contended that the organic coatings were successful in promoting good quality dropwise condensation for prolonged periods of times ( $>12,000 \mathrm{~h}$ ). They obtained dropwise heat transfer coefficients as large as six times the film condensation value and the results were not dependent upon the thermal conductivity of the wall. Inorganic coatings were also examined. Some researchers have investigated dropwise condensation of diamond-like-coatings (DLCs) and ionimplanted coatings on aluminum and copper plates [83, $110,111,112]$. Koch et al. [82] reported that the

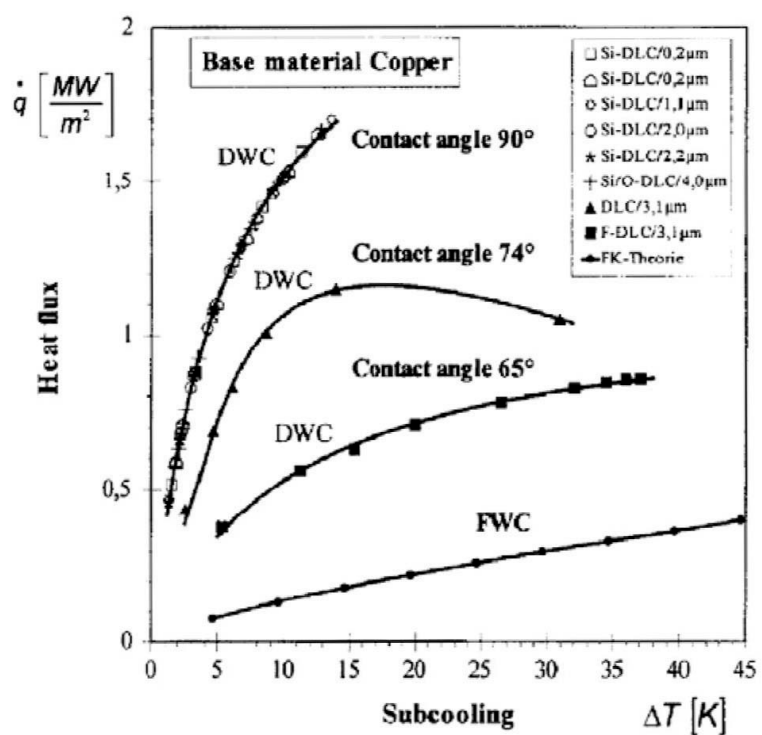

Fig. 21. Dependence of the Heat Flux on the Contact Angle [82]

dropwise condensation heat transfer rate increased with an increase in the contact angle, as shown in Fig. 21. Rausch et al. [83] argued that ion-implanted aluminum surfaces showed 5-fold higher dropwise condensation heat transfer performance than filmwise condensation. Recently, graphene films and graphene sheets have attracted a great deal of attention. Wettability and wetting control in graphene films have been investigated [113, 114] although condensing heat transfer is not yet of widespread interest.

Numerous studies have considered industrial applications instead of focusing on phenomenological observations. Vemuri et al. [108] created hydrophobic coatings through self-assembled monolayers (SAMs) of n-octadecylmercaptan and stearic acid on copper alloy circular tubes. They measured dropwise condensation heat flux on circular tube walls and reported that the condensation heat transfer rate was increased by a factor of 3 to 1.8 times depending on the operating conditions. Kananeh et al. [112] also achieved stable dropwise condensation of saturated steam on a horizontal stainless- 
Fabrication techniques for creating micro/nano textured surface

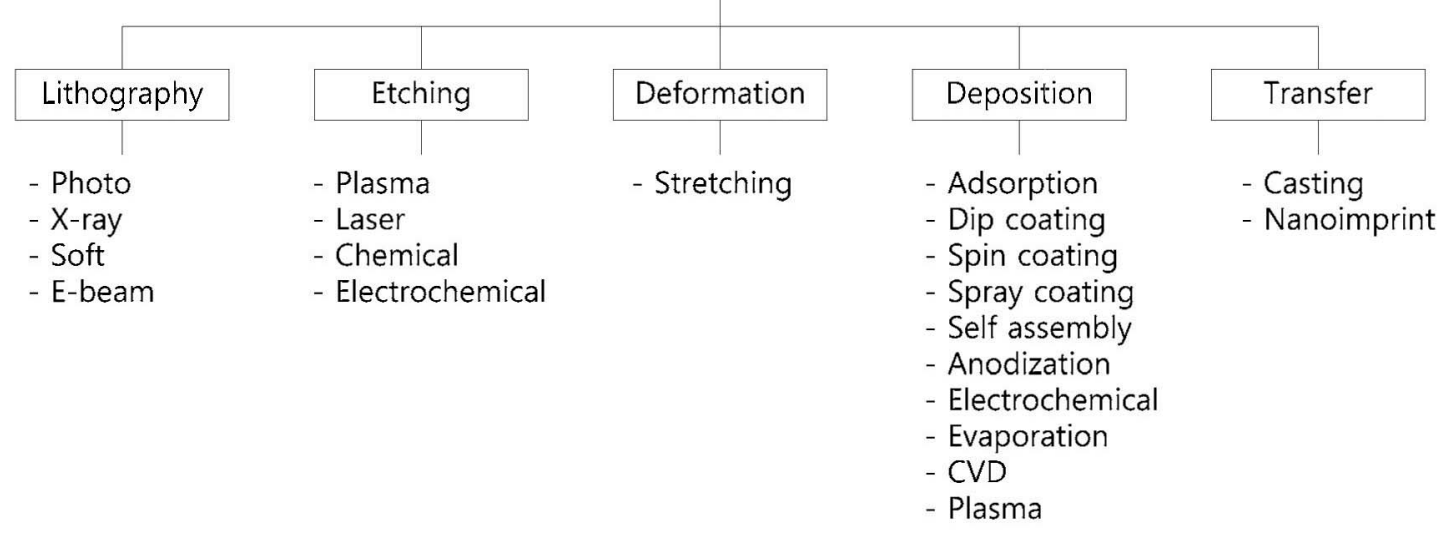

Fig. 22. Typical Methods to Fabricate Micro/nano Textured Surfaces [115]

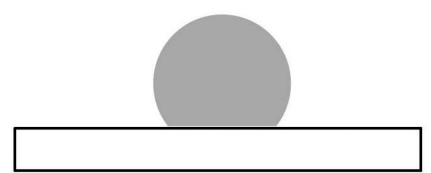

(a) coated surface

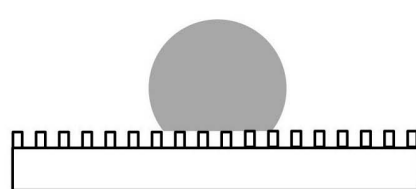

(b) nano-patterned surface

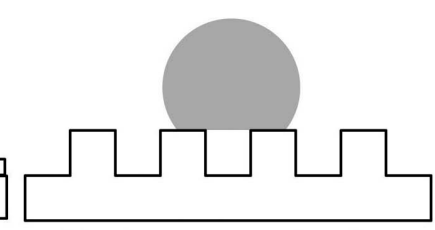

(c) micro-patterned surface

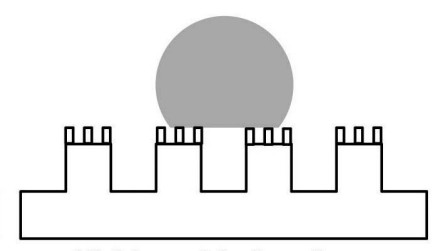

(d) hierarchical surface

Fig. 23. Morphologies of Hydrophobic Surface

steel tube bundle of nine tubes implanted with nitrogen ions. They reported the overall heat transfer coefficient of the implanted tube bundle was increased by 1.12 times compared to that of an unimplanted bundle. They also reported that more dropwise condensation was formed on the upper tube rows at promoted conditions, while the lowest row received more condensate, and the condensation form was thereupon converted to filmwise condensation. It should be noted that the contact angle concept is used as a measure of the hydrophobicity of a coated surface; however, for accurate prediction of the DWC characteristics, experiments should be conducted. For example, in a study by Vemuri et al. [108], stearic acid, which has a contact angle of $155^{\circ}$, did not show DWC mode when experiments were carried out.

\subsubsection{DWC on Textured Surface}

Textured hydrophobic surface can lead to enhanced heat transfer by achieving drop-wise condensation, upon which condensate droplets are produced and roll down the surface to reproduce a dry surface with the result that the thermal resistance due to the condensate is minimized. Hydrophobic surfaces can be fabricated by various methods. Recent advancements of micro- and nano-size process technologies have made the fabrication of nano-size structures on flat surfaces possible. Superhydrophobic surfaces have been created using a wide variety of techniques including lithography and coating techniques. Fig. 22 shows a wide variety of fabrication techniques for creating micro/nanostructures on surfaces[115]. Hydrophobic materials are commonly applied onto textured surfaces to promote hydrophobicity. Teflon [116, 117], PFOS (perfluoro-octane sulfonates) [118], PDMS (polydimethylsiloxane) [119], and CNTs (carbon nanotubes) $[120,121,122]$ are representative examples. CVD (chemical vapor deposition), PVD (plasma vapor deposition), and electrochemical deposition techniques are commonly used to coat these materials. However, it is thus far evident that these coating methods do not provide sufficient durability, as the hydrophobic coating materials are generally fragile and aging can also be problematic. As such, many issues must be resolved before these techniques can find industrial applications.

Various textured surfaces have been fabricated by many researchers in efforts to develop hydrophobic surfaces. Various morphologies of hydrophobic surfaces have been reported in the open literature, and some notable examples are illustrated in Fig. 23. Possible results include modified flat surfaces, micro-patterned surfaces, nano-patterned surfaces, and micro/nano-patterned 
surfaces. The textured surfaces can be classified into two categories: irregular-patterned surfaces and regular patterned surfaces. The patterned surfaces can be utilized as biomimetic artificial surfaces to investigate the effects of micro-/nano-structures on hydrophobic characteristics. Since the observation of a hydrophobic lotus leaf by Barthlott and Neinhuis [92], there has been significant progress in understanding of hydrophobic characteristics of textured surfaces due to advanced biomimetics and micro-/nano- structured surface fabrication techniques [123].

Previous investigations of hydrophobic textured surfaces focused on the wetting behavior of macroscopic water drops on the surfaces. Some researchers endeavored to elucidate the Cassie-Wenzel transition where the condensate droplet changes from a Wenzel state to a Cassie-Baxter state [124,125, 126]. The interrelationship among surface material state, surface morphology, and droplet states should be explicated in order to obtain the transition criterion. Nosonovsky and Bhushan [125] proposed generalized Cassie-Wenzel equations and argued that the Cassie-Wenzel transition cannot be determined from macroscale equations and rather is governed by micro- and nanoscale effects; in other words, the CassieWenzel transition involve processes on the nanoscale. Choi et al. [124] also proposed a modified Cassie-Baxter relation to include a local differential texture parameter that enables quantitative prediction of the apparent advancing and receding contact angles.

Condensation on hydrophobic textured surfaces has also been studied. Since the first report on vapor condensation on a hydrophobic artificial microstructure surface [122], some attention has been paid to dropwise condensation on hydrophobic surfaces. Since Cheng et al. [127] reported the first in situ observation of water condensation on lotus leaf surfaces using an environmental scanning electron microscope (ESEM), some researchers $[127,128,129]$ have investigated condensation on hydrophobic plant leaves. Other groups have meanwhile studied dropwise condensation on surfaces with artificial micro- and nanostructures [95, 130, 131, 132, 133]. The condensation on lotus leaves shows that the lotus leaves can be either hydrophobic or hydrophilic depending on how the water comes into contact with their surfaces. The condensed droplets may adhere to the surface despite having very high apparent contact angles [127, 128] or they may be suspended on the tops of papillae due to hydrophilicity [129]. Zheng et al. [129] contended that the dynamic suspension of condensed droplets can be attributed to a wettability gradient dependence of the micro- and nanostructures via water condensation, which introduces unbalanced surface tension. In order to control the nucleation sites, Varanasi et al. [132] fabricated artificially textured hydrophobic surfaces with hydrophilic tops. This surface promoted nucleation and growth of Cassie-type droplets and can therefore exhibit superior droplet shedding properties under condensation. Chen et al. [95] achieved continuous dropwise condensation on an artificial two-tier texture, mimicking that on the surface of lotus leaves, with short carbon nanotubes deposited on micromachined pillars. Hexadecanethiol-coated two-tier textures appeared to surpass lotus leaves in terms of retaining superhydrophobicity during and after laboratory condensation.

Experimental measurements by the author's laboratory showed that dropwise condensation might not take place even on a superhydrophobic textured surface. When a liquid droplet falls onto a hydrophobic textured surface, it rebounds several times before coming to a standstill on the surface, and the contact angle is $152^{\circ}$. When this surface was tested to measure the condensing heat transfer rate, dropwise condensation did not occur and the condensing heat transfer rate was close to the prediction by Nusselt's film condensation model. The ESEM images of this specimen showed that the condensate might nucleate on the bottom surface as well as on the vertical walls of structures when steam condenses. These droplets grow and fill the valley to form a Wenzel state. In this case, the condensate would not roll down the surface but instead tends to adhere to the textured surface. Some articles have reported similar observations on lotus leaves. Cheng and Rodak [128] reported that the lotus leaf exhibited superhydrophobic behavior when water drops of macroscopic size were placed on its surface. However, the lotus effect vanished when water was condensed onto its surface from the vapor phase. Zheng et al. [129] observed a process where a small micro-droplet is initiated in the valley of papillae, grows to form a bead, and coalesces with the surrounding small micro-droplets. When the size of the micro-droplet corresponds with that of the valley, this micro-droplet is deformed and tends to move out of the valley, and is finally suspended on the tops of the papillae. Before Zheng et al.[129] reported this, Wier and McCarthy [130] reported similar observations for silicon based textured surfaces. While there have been other corresponding observations, previous researchers have not suggested sound mechanisms and theories about this process. In order to develop a surface facilitating stable DWC, it is necessary to understand the mechanism underlying how a liquid droplet changes its state from a Wenzel state to Cassie-Baxter state. Also, it is critical to understand where nucleation is initiated.

\subsubsection{DWC Performance Evaluation under Industrial Conditions}

FWC models for laminar free convection film condensation on an isothermal vertical plate and on an isothermal horizontal tube were established by Nusselt [79]. The Nusselt model assumes equilibrium at the condensate-vapor interface, and thus the temperature at the outer surface of the condensate film was taken as the 
vapor temperature. This model neglects inertia/ acceleration in the film, convection in the film, and shear stress from the vapor at the surface of the condensate film. In spite of these simplifications, this model is known to be remarkably accurate in the practical ranges of the relevant parameters [134].

The heat transfer performance of DWC is superior to that of FWC because the thermal resistance between the surface and vapor reduces significantly due to rapid draining of the condensate. DWC was first noted by Schmidt et al. [135] but only became understood in the 1960s. A wealth of experimental data on DWC was generated in the 1930s through 1950s. Until the 1960s, however, the experimental data was broadly scattered. There were wide discrepancies between the results of different investigators. This discrepancy was mainly caused by the effects of non-condensable gas. As the experiments were performed without a non-condensable gas, experimental measurements on DWC performance showed consistency and the mechanism and theory of the DWC are now better understood [106, 136].

The presence of a non-condensable gas has a dominant effect on the heat transfer performance over other parameters including even the condensation mode. The non-condensable gas will move toward a condensing wall and accumulate as steam condenses. The accumulated steam will act as a thermal resistance and a barrier to steam diffusion. The effect of non-condensable gas is thus detrimental to vapor condensation regardless of the condensation mode. It was shown that the condensation heat flux is very sensitive to the presence of even a small amount of air (order of ppm), as can be seen in Fig. 24 [137, 138, 139]. The presence of a non-condensable gas is also associated with the effect of surface inclination.

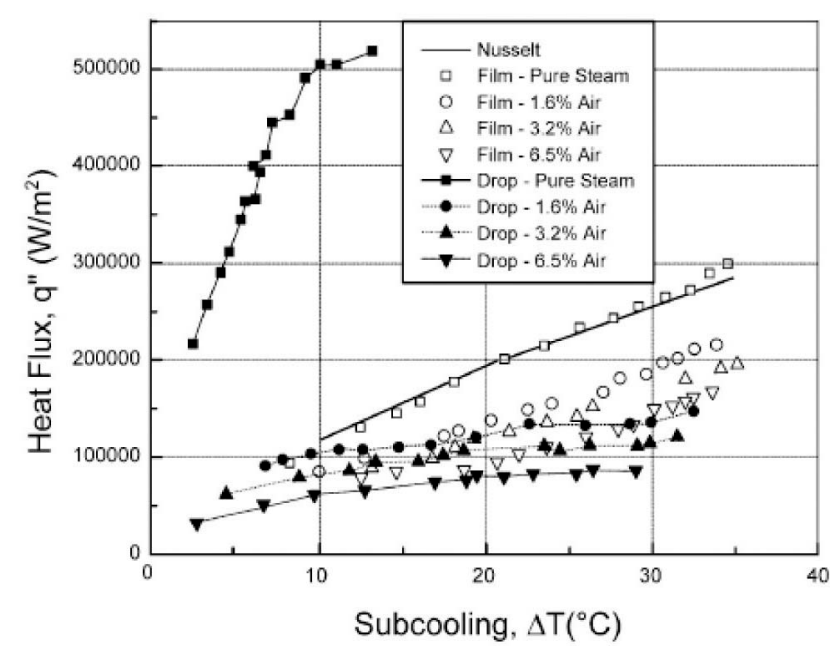

Fig. 24. The Effects of Air on Filmwise and Dropwise Condensation Heat Flux with Air on a Vertical Surface [139]
When a flat condensing surface is tilted, the downward facing surface has larger condensing heat flux than the upward-facing surface. This is because the non-condensable gas may accumulate on the upward-facing surface while it escapes from the downward-facing surface due to a density difference $[137,160]$.

The effects of vapor pressure on condensation heat transfer were experimentally investigated by researchers $[108,112,140,141]$. The trends of the previous works all agree well. The condensation heat transfer at an elevated pressure was larger than that at low pressure. Vemuri et al. [108] created hydrophobic coatings through self-assembled monolayers (SAMs) of n-octadecylmercaptan and stearic acid on copper alloy circular tubes. They measured dropwise condensation heat flux on circular tube walls with variation of the vapor pressure. When the vapor pressure was increased from $33.86 \mathrm{kPa}$ to $101 \mathrm{kPa}$, the condensation heat transfer rate was increased by a factor of about 2.6. Kananeh et al. [112] also achieved stable dropwise condensation of saturated steam on a horizontal stainless-steel tube bundle of nine tubes implanted with nitrogen ions. The enhancement ratio, which represents the ratio of the overall heat transfer coefficient of the implanted tube bundle to that of the unimplanted bundle, was found to be 1.12 for a coolingwater Reynolds number of about 21,000. The heat flow and the overall heat transfer coefficient were increased by increasing the steam pressure. Junjie et al. [141] investigated the effects of vapor pressure on condensation heat transfer for a steam-ethanol vapor mixture. Their observations also reflect the same trends as previous works on pressure effects.

\section{FUTURE PROSPECTS AND DIRECTIONS}

In closing, while the challenges of advancing the science and engineering of boiling and condensation will expand significantly in the near future, nanotechnology is the most likely technique to be introduced, as progress via other macro/micro scale-based technologies has been saturated. These will undoubtedly be driven by the world's ever increasing energy needs for domestic and industrial consumption as well as application of nuclear safety systems in passive components and related design needs. This special issue and its collection of technical contributions certainly reflect this direction in Advanced Nuclear Thermal-Hydraulics and Safety secured by advancing boiling and condensation.

This paper concludes with a summary of the recommendations and future directions for boiling and condensation, as provided below.

\section{For boiling:}

Nanotechnology for boiling has been classified into nanostructured surface technology and nanofluid technology. Through the review, boiling and $\mathrm{CHF}$ 
Table 1. Surface Tension of Liquids (N/m)

\begin{tabular}{c|c|c|c|c|c}
\hline Sat. Pres. & $\mathrm{H}_{2} \mathrm{O}$ & $\mathrm{NH}_{3}$ & $\mathrm{R}-22$ & $\mathrm{R}-134 \mathrm{a}$ & $\mathrm{R}-410 \mathrm{a}$ \\
\hline $100 \mathrm{kPa}$ & 0.05898 & $3.421 \times 10^{-2}$ & $1.824 \times 10^{-2}$ & $1.548 \times 10^{-2}$ & $1.824 \times 10^{-2}$ \\
\hline $1,000 \mathrm{kPa}$ & 0.04221 & $2.134 \times 10^{-2}$ & $8.327 \times 10^{-3}$ & $6.207 \times 10^{-3}$ & $8.327 \times 10^{-3}$ \\
\hline $4,000 \mathrm{kPa}$ & 0.02595 & $1.009 \times 10^{-2}$ & $8.638 \times 10^{-4}$ & $2.285 \times 10^{-5}$ & $8.638 \times 10^{-4}$ \\
\hline
\end{tabular}

performance are apparently driven by the surface wettability, with the result that both involve fundamentally the same surface-modification technology. The first question raised here is which is better for nuclear applications. A second issue is that existing studies have not considered the actual situations with complex problems based on crud or corrosion-related materials deposition phenomena in long-term operation of reactor systems [7]. The last is what phenomena in nanotechnology-introduced boiling are different from previously identified macro/micro-structures-induced boiling phenomena.

Specifically, further studies on the following topics should be conducted in the near future.

- How to enhance BHT with nanofluids?

- Mechanisms to enhance flow boiling heat transfer and $\mathrm{CHF}$

- Effects of other major thermal-hydraulic parameters such as pressure, mass flux, subcooling, and so on.

- Consideration of crud effects in relatively long-term operation

\section{For condensation:}

As the heat transfer performance in dropwise condensation mode is superior to that in filmwise condensaton mode, the performance of a heat rejection system will be improved if dropwise condensation is facilitated with the system. Dropwise condensation takes place on a hydrophobic surface where the contact angle is larger than 90 degrees. Since hydrophobicity is caused by the balance of surface energies of a liquid and solid, as the surface tension of a fluid becomes higher the likelihood that dropwise condensation will take place on a heat transfer wall accordingly rises. It should be noted that dropwise condensation only occurs with a few relatively high surface tension fluids - notably steam, a few organic fluids, and mercury (Table 1 in N/m)

Most current nuclear power plants are water-cooled. These reactors make use of water as a heat transfer medium under normal and even abnormal operating conditions. In this regard, the dropwise condensation mode has major potential applications to sub-systems and components of nuclear power plants.

Recent advancements in micro- and nano- size process technologies and measurement technologies have allowed various designs of micro-/nano- structures and diverse research on the characterization of hydrophobic surfaces.
However, the understanding of the mechanism and theory concerning dropwise condensation on hydrophobic textured surfaces is not sufficient. Reliable methods for promoting dropwise condensation under industrial conditions also need to be developed. The condenser designer will wish to know the bounding conditions where the condenser can benefit from DWC. When a condenser is constructed with a horizontal tube bundle, dropwise condensation on the upper rows will produce more condensate, and consequently the condensation mode on the lower rows will change to filmwise condensation. The longevity of dropwise condensation is also crucial. The surface of a heat transfer tube will be fouled as the operation period increases and the surface morphology may change such that dropwise condensation is not sustained. Lastly, economical fabrication techniques for hydrophobic surfaces should be developed. For example, printing methods, spray methods, and structure growth in controlled environments can be explored.

\section{ACKNOWLEDGMENTS}

The work is supported by the Nuclear Research and Development Program through the National Research Foundation of Korea (NRF) funded by the Ministry of Education, Science and Technology. The work of J.H. Jeong was also partially supported by a Korea Institute of Energy Technology Evaluation and Planning(KETEP) grant funded by the Korean Ministry of Knowledge Economy (2009T 100100560). The authors would like to thank Mr. Kiwook Kim for his help to produce illustrations related to condensation. Special thanks to Prof. Jacopo Buongiorno at MIT for reviewing the article.

\section{REFERENCES}

[ 1 ] I.C. Bang, TokyoTech Chronicle, 2008

[2] R. M. Manglik, On the Advancements in Boiling, TwoPhase Flow Heat Transfer, and Interfacial Phenomena, Journal of Heat Transfer, 2006

[3] Incropera and Dewitt, Fundamentals of Heat and Mass Transfer, Four Edition, Wiley

[4] M.M. El-wakil, Nuclear Heat Transport, The American Nuclear Society, 1993

[5] J.C. Vigil and R. J. Pryor, "Accident simulation with TRAC”, Los Alamos Science, No.3 1981.

[6] J.J. Rempe, K.Y. Suh, F.B. Cheung, S.B. Kim, "In-vessel retention of molten corium: lessons learned and 
outstanding issues", Nuclear Technology, Vol. 161, 210, 2008.

[ 7 ] I.C. Bang and J.H. Kim, Thermal-Fluid Characterizations of $\mathrm{ZnO}$ and SiCnanofluids for advanced nuclear power plants.

[ 8 ] S.H. Chang, W.P. Baek, Understanding, predicting, and enhancing critical heat flux, in: The 10th International Topical Meeting on Nuclear Reactor Thermal Hydrualics (NURETH-10), Seoul, Korea, October (5-9) 2003.

[9] C.H. Li, et al. Comparison study of liquid replenishing impacts on critical heat flux and heat transfer coefficient of nucleate pool boiling on multiscale modulated porous structures, Int. J of Heat and Mass Transfer 54, 31463155,2011

[10] http://en.wikipedia.org/wiki/Nanotechnology

[11] W.Fritz, 1935, "Berechnung des Maximal Volume von Dampfblasen", Phys. Z., 36, 379.

[12] N. Zuber, 1963, "Nucleate boiling - the region of isolated bubbles - similarity with natural convection", Int. J. Heat Mass Transfer, 6, 53.

[13] C.H. Wang and V. K. Dhir, 1993, "Effect of surface wettability on active nucleation site density during pool boiling of water on a vertical surface", J. Heat Transfer, vol. 115, 659-669.

[14] R.N.Wenzel, 1949, "Surface roughness and contact angle (letter)", J. Physical Colloid Chemistry, 53, 9, 1466.

[15] S. S.Kutateladze, and A. I. Leont'ev, 1964, Turbulent boundary layers in compressible gases, D. B. Spalding, Trans., Academic Press, New York.

[16] N. Zuber, 1959, Hydrodynamic Aspects of Boiling Heat Transfer, AECU-4439.

[17] T.G. Theofanous et al., 2002, "The boiling crisis phenomenon. Part II: dryout dynamics and burnout", Experimental Thermal and Fluid Science, 26, 793-810.

[18] Y. Haramura and Y. Katto, 1983, "A new hydrodynamic model of CHF applicable widely to both pool and forced convection boiling on submerged bodies in saturated liquids", Int. J. of Heat and Mass Transfer, 26, 389-399.

[19] P. Sadasivan, P. R. Chappidi, C. Unal, and R. A. Nelson, 1992, "Possible Mechanisms of Macrolayer Formation", Pool and External Flow Boiling (ASME 1992) p. 135.

[20] T.G. Theofanous and T. N. Dinh, 2006, "High heat flux boiling and burnout as microphysical phenomena: mounting evidence and opportunities", Multiphase Science and Technology, Vol. 18, No. 1, pp. 1-26.

[21] W. Rosenhow and P. Griffith, 1956, "Correlation of Maximum Heat Flux Data for Boiling of Saturated Liquids", Chem. Eng. Prog. Symp. Ser. 52, 18, 47-49.

[22] N. Kolev, 2002, "How accurately can we predict nucleate boiling?", in Multiphase Flow Dynamics 2, Springer.

[23] S.G. Kandlikar, A theoretical model to predict pool boiling CHF incorporating effects of contact angle and orientation, J. Heat Transfer 123 (2001) 1071-1079.

[24] S.G. Liter and M. Kavinay, "Pool-boiling CHF enhancement by modulated porous-layer coating: Theory and experiment," Int. J. Heat and Mass Transfer, vol. 44, pp. 4287-4311, 2001.

[25] S. D. Park, S. W. Lee, S. Kang, I. C. Bang, J. H. Kim, H. S. Shin, D. W. Lee, and D. W. Lee, Effects of nanofluids containing graphene/graphene-oxide nanosheets on critical heat flux, Appl. Phys. Lett. 97, 023103 (2010)
[26] I.C. Bang, J. Buongiorno, L.W. Hu, H. Wang, Measurement of key pool boiling parameters in nanofluids for nuclear applications, JSME Journal of Power and Energy Systems, Vol. 2, No. 1, (2008)

[27] R. Ahmed, Coolants for nuclear reactors, available on the Internet at http://www.nuc.berkeley.edu/thyd/ne161/ rahmed/coolants.html

[28] R. Chen, Nanowires for enhanced boiling heat transfer, nano letters, 2009, vol. 9, No. 2, 548-553.

[29] C. Li, Zuankai Wang1, Pei-I Wang, YoavPeles, Nikhil Koratkar, G. P. Peterson, Nanostructured Copper Interfaces for Enhanced Boiling, Small, Volume 4, Issue 8, pages 1084-1088, August 2008

[30] M. Sesen et al. "Compact nanostructure integrated pool boiler for microscale cooling applications", Micro \&nano Letters, 2010, Vol. 5, 203-206

[31] H.S. Ahn et al. "Pool Boiling Experiments on a NanoStructured Surface”, IEEE Transactions on components and packaging technologies, vol. 32, No. 1, 2009.

[32] T.J. Hendricksa, Shankar Krishnana, ChanghoChoib, Chih-Hung Changb and Brian Paulc, Enhancement of pool-boiling heat transfer using nanostructured surfaces on aluminum and copper, International Journal of Heat and Mass Transfer, Volume 53, Issues 15-16, July 2010, 33573365

[33] H.S. Ahn, et al. "Pool boiling CHF enhancement by micro/nanoscale modification of Zircaloy-4 surface," Nuclear Engineering and Design, Vol. 240, Issue 10, pp. 3350-3360. (2010)

[34] E. Forrest et al. "Augmentation of nucleate boiling heat transfer and critical heat flux using nanoparticle thin-film coatings", Int. Journal of Heat and Mass Transfer, (2010), vol. 53, 58-67

[35] S. Jeon, P. Roy, N. K. Anand, D. Banerjee, "Investigation of Flow Boiling on Nanostructured Surfaces, 2010 14th International Heat Transfer Conference (IHTC14), August 8-13, 2010, Washington, DC, USA, Paper no. IHTC1422926 pp. 577-582 doi:10.1115/I HTC14-22926

[36] S.U.S. Choi, "Enhancing thermal conductivity of fluids with nanoparticles", Developments and Applications of Non-Newtonian Flows, FED-vol. 231/MD-vol. 66, 1995

[37] J.F. Hoegerton, and R.C. Grass, Reactor Handbook, Vol. 3, Engineering, Selected Reference Material, U.S. Atomic Energy Commission, August 1955.

[38] A.A. Taylor, P.E. Phelan, Pool Boiling of nanofluids: Comprehensive review of existing data and limited new data, Int .J. of Heat and Mass Transfer 52, 5339-5347, 2009.

[39] S.M. S. Murshed, C.A. N. D. Castro, M.J.V. Lourenco, M.L.M. Lopes, F.J.V. Santos, A review of boiling and convective heat transfer with nanofluids, Renewable and Sustainable Energy Reviews 15, 2342-2354, 2011.

[40] J. Barber, D. Brutin and L. Tadrist, A review on boiling heat transfer enhancement with nanofluids, Nanoscale Research Letters, 2011.

[41] S.K. Das, N. Putra and W. Roetzel, Pool boiling characteristics of nano-fluids, Int. J. Heat Mass Transfer 46 (2003), pp. 851-862.

[42] I.C. Bang and S.H. Chang, Boiling heat transfer performance and phenomena of $\mathrm{Al}_{2} \mathrm{O}_{3}$-water nano-fluids from a plain surface in a pool, International Journal of 
Heat and Mass Transfer Volume 48, Issue 12, June 2005, Pages 2407-2419

[43] S. M You., J. Kim, K. H. Kim, Effect of nanoparticles on critical heat flux of water in pool boiling heat transfer, Applied Physics Letters, 83, 16, 3374-3376. (2003)

[44] P. Vassallo, R. Kumar, S. D'Amico, "Pool boiling heat transfer experiments in silica-water nano-fluids", Int. J. of Heat and Mass Transfer, 47, 407-411. (2004)

[45] D. Wen and Y.Ding, Experimental investigation into the pool boiling heat transfer of aqueous based c-alumina nanofluids, Journal of Nanoparticle Research (2005) 7: 265-274

[46] K. J.Park, D.Jung, Enhancement of nucleate boiling heat transfer using carbon nanotubes. Int J Heat Mass Transfer (2007) 50:4499-4502.

[47] A.Suriyawong, S.Wongwises, Nucleate pool boiling heat transfer characteristics of $\mathrm{TiO}_{2}$-water nanofluids at very low concentrations. ExpTherm Fluid Sci, 34(8):992-999. (2010)

[48] Z-H. Liu,X-F. Yang, J-G Xiong, Boiling characteristics of carbon nanotube suspensions under sub-atmospheric pressures. Int J ThermSci, 49(7):1156-1164. (2010)

[49] D. Milanova and R. Kumar, Role of ions in pool boiling heat transfer of pure and silica nanofluids, Appl. Phys. Lett. 87, 233107, (2001).

[50] S.J. Kim, I. C.Bang, J.Buongiorno, L.W. Hu, "Effects of nanoparticle deposition on surface wettability influencing boiling heat transfer in nanofluids", Applied Physics Letters 89, 153107 (2006)

[51] H.D. Kim and M. H. Kim, Effect of nanoparticle deposition on capillary wicking that influences the critical heat flux in nanofluids, Appl. Phys. Lett. 91, 014104 (2007)

[52] G.S. Hwang and M. Kavinay, "Critical heat flux in thin, uniform particle coatings," Int. J. Heat and Mass Transfer, vol. 49, pp. 844-849, (2006)

[53] S.J. Kim, T. McKrell, J. Buongiorno, and L.-W. Hu, "Alumina Nanoparticles enhance the flow boiling critical heat flux of water at low pressure", Journal of Heat Transfesr, vol 130, 044501, (2008)

[54] S.J. Kim, T. McKrell, J. Buongiorno, and L.-W. Hu, Experimental Study of Flow Critical Heat Flux in Alumina-Water, Zinc-Oxide-Water, and Diamond-Water Nanofluids, J. Heat Transfer -- April 2009 -- Volume 131, Issue 4, 043204

[55] S.J. Kim, T. McKrell, J. Buongiorno, and L.-W. Hu, Subcooled flow boiling heat transfer of dilute alumina, zinc oxide, and diamond nanofluids at atmospheric pressure, Nuclear Engineering and Design 240 1186-1194 (2010)

[56] B.Truong, J.Buongiorno L.Hu, T.McKrell, "Alumina Nanoparticle Pre-Coated Tubing Enhancing Subcooled Flow Boiling Critical Heat Flux", ASME 2009 Second International Conference on Micro/Nanoscale Heat and Mass Transfer, Volume 1, Paper no. MNHMT 200918364 pp. 533-539

[57] K. Henderson, Y. Park, L. Liu, Anthony M. Jacobi, Flowboiling heat transfer of R-134a-based nanofluids in a horizontal tube, International Journal of Heat and Mass Transfer 53 944-951 (2010)

[58] H.S. Ahn, H. Kim, H. Jo, S. Kang, W. Chang, M. H. Kim,
Experimental study of critical heat flux enhancement during forced convective flow boiling of nanofluid on a short heated surface, International Journal of Multiphase Flow 36 375-384 (2010)

[59] T.I. Kim, W. J. Chang, S. H. Chang, Flow boiling CHF enhancement using $\mathrm{Al}_{2} \mathrm{O}_{3}$ nanofluid and an $\mathrm{Al}_{2} \mathrm{O}_{3}$ nanoparticle deposited tube, Int. J. of Heat and Mass Transfer 54, 2021-2025, (2011)

[60] S.Vafaei and D. Wen, Critical Heat Flux (CHF) of Subcooled Flow Boiling of Alumina Nanofluids in a Horizontal Microchannel, J. Heat Transfer, Vol. 132, Issue 10, 102404 (2010)

[61] S.Vafaei and D. Wen, Flow boiling heat transfer of alumina nanofluids in singlemicrochannels and the roles of nanoparticles, J Nanopart Res 13:1063-1073. (2011)

[62] H.S. Ahn, S. H. Kang, H. Jo, H. Kim, M. H. Kim, Visualization study of the effects of nanoparticles surface deposition on convective flow boiling CHF from a short heated wall, Int. J. of Multiphase Flow 37, 215-228, (2011)

[63] S.W. Lee, S.D. Park, S. Kang, S.M. Kim, D.W. Lee, I.C. Bang, Investigation of critical heat flux enhancement in flow boiling using nanofluids, Transactions of the Korean Nuclear Society Spring Meeting, Taebaek, Korea, May, (2011)

[64] H.S.Park, D.Shiferaw, B.R.Sehgal, D.K.Kim, M.Muhammed, Film boiling heat transfer on a high temperature sphere in nanofluid. In: Proceedings of 2004 ASME Heat Transfer/ Fluids Engineering Summer Conference, Charlotte, NC, pp. 1-8. (2004)

[65] H.S. Xue, J.R. Fan, R.H.Hong, Y.C.Hu, Characteristic boiling curve of carbon nanotube nanofluid as determined by the transient calorimeter technique. Appl. Phys. Lett. 90, 184107. (2007)

[66] H. Lotfi, M.B. Shafii, Boiling heat transfer on a high temperature silver sphere in nanofluids, Int. J. Thermal Sci. 48 2215-2220. (2009)

[67] I.C. Bang, Effects of nanoparticles on single rod quenching, in: Proceedings of the Sixth Japan-Korea Symposium on Nuclear Thermal Hydraulic and Safety, Okinawa, Japan, (2008)

[68] H. Kim, G. DeWitt, T. McKrell, J. Buongiorno, L.W. Hu, On the quenching of steel and zircaloy spheres in waterbased nanofluids with alumina, silica and diamond nanoparticles, International Journal of Multiphase Flow 35 427-438. (2009)

[69] H. Kim, J. Buongiorno, L.W. Hu, T. McKrell, Nanoparticle deposition effects on the minimum heat flux point and quench front speed during quenching in water-based alumina nanofluids, Int. J. Heat Mass Transfer 53 1542-1553. (2010)

[70] S. Chun, I. C. Bang, Y. Choo, C. Song, Heat transfer characteristics of $\mathrm{Si}$ and $\mathrm{SiCnanofluids}$ during a rapid quenching and nanoparticles deposition effects, International Journal of Heat and Mass Transfer 54 1217-1223 (2011)

[71] A.Bolukbasi, D.Ciloglu, "Pool boiling heat transfer characteristics of vertical cylinder quenched by $\mathrm{SiO}_{2}$-water nanofluids", International Journal of Thermal Sciences 50 1013-1021 (2011)

[72] D.Ciloglu, A.Bolukbasi, "The quenching behavior of 
aqueous nanofluids around rods with high temperature", doi:10.1016/j.nucengdes.2011.04.023 (2011)

[73] I.C. Bang, Direct observation of dryout processes of thin liquid films and $\mathrm{Al}_{2} \mathrm{O}_{3}$ nanofluids performance in boiling crisis, KAIST Ph.D Thesis, (2004)

[74] J. Buongiorno and L.-W. Hu, "Nanofluid Coolants for Advanced Nuclear Power Plants", Paper 5705, Proceedings of ICAPP '05, Seoul, May 15-19. (2005)

[75] K. Hadad, A. Hajizadeh, K. Jafarpour, B.D. Ganapol, Neutronic study of nanofluids application to VVER-1000, Annals of Nuclear Energy 37, 1447-1455, (2010)

[76] J. Buongiorno, L.W. Hu, G. Apostolakis, R. Hannink, T. Jucas, A. Chupin, A feasibility assessment of the use of nanofluids to enhance the in-vessel retention capability in light-water reactors. Nuclear Engineering and Design 239, 941-948, (2009)

[77] I.C. Bang, G. Heo, Y.H. Jeong, S. Heo, An axiomatic design approach of nanofluid-engineered nuclear safety features for generation III+ Reactors, Nuclear Engineering and Technology, Vol. 41, No.9, 1157-1170, (2009)

[78] M. Kang, C. Jee, S. Park, I.C. Bang, G. Heo, Design process of the nanofluid injection mechanism in nuclear power plants, Nanoscale Research Letters, 6:363 (2011)

[79] W.Nusselt, "Die oberflachenkondensation des wasserdampfes," Z VereinesDeutchIng, 60(27), pp.541546, (1916).

[80] Q. Zhao, D. C. Zhang, J. F. Lin, G. M. Wang, "Dropwise condensation on L-B film surface," Chem. Eng. Process, 35, pp. 473-477 (1996).

[81] K. B. Blodgett, "Films built up by depositing successive mono- molecular layers on a solid surface," J. Am. Chem. Soc, 57, pp. 1007-1022 (1935).

[82] G. Koch, K. Kraft, A. Leipertz, "Parameter study on the performance of dropwise condensation," Rev. Gen. Therm., 37, pp. 539-548, 1998.

[83] M.H. Rausch, A.P. Froba and A. Leipertz, "Dropwise condensation heat transfer on ion implanted aluminum surfaces," Int. J. Heat Mass Transfer, 51, pp. 1061-1070 (2008).

[84] K. Watanabe, "Fluid frictions of shark skin and lotus leaf How does the drag reduction occur?" J. Jap. Soc. Tribol., 45, pp. 354-359 (2000).

[85] R.P. Andrew, C.R. Lawrence, "Water capture by a desert beetle," Nature, 414, pp. 33-34, (2001).

[86] C. Neinhuis, W. Barthlott, "Characterization and distribution of water-repellent, self-cleaning plant surfaces", Ann. Botany, 79(6): 667-677, (1997).

[87] M. Callies, D. Quere, "On water repellency," Soft Matter, 1, pp. 55-61,(2005).

[88] C. V. Boys, "Soap bubbles and the forces which mould them", Society for Promoting Christian Knowledge, London, 1902.

[89] F.M. Fowkes, "Contact angle, wettability, and adhesion," Advances in chemistry series, 43, American Chemical Society, Washington, 1964.

[90] P.G. De Gennes, "Wetting: statics and dynamics," Rev Mod Physics, 57, pp. 827-863 (1985).

[91] A.W. Adamson, "Physical chemistry of surfaces" Wiley, London, 1990.

[92] W. Barthlott, C. Neinhuis, "Purity of the sacred lotus, or escape from contamination in biological surfaces," Planta,
202, pp. 1-8, (1997).

[93] T. Onda, S. Shibuichi, N. Satoh, and K. Tsujii, "Superwater-repellent fractal surfaces," Langmuir, 12, pp. 21252127 (1996).

[94] J. Bico, C. Marzolin, D. Quéré, "Pearl drops," Europhysics Letters, 47(2), pp.220-226 (1999).

[95] C.H. Chen, Q. Cai, C. Tsai, C.L. Chen, "Dropwise condensation on superhydrophobic surfaces with two-tier roughness", Applied Physics Letter, 90, 173108, (2007).

[96] L. Zhang, Z. Zhou, B. Cheng, J.M. DeSimone, E.T. Samulski, "Superhydrophobic behavior of a perfluoropolyether lotus-leaf-like topography," Langmuir, 22, pp.8576-8580 (2006).

[97] A.V. Adamson, "Physical chemistry of surfaces", Wiley, 1990.

[98] T. Young , "An essay on the cohesion of fluids," Phil. Trans. R. Soc. Lond., 95, pp. 65-87, (1805).

[99] R.N. Wenzel, "Resistance of solid surfaces to wetting by water", Industrial and Engineering Chemistry, 28, pp. 988994 (1936)

[100] R.N. Wenzel, "Surface roughness and contact angle," Journal of Physical Colloid Chemistry, 53(9), pp. 14661467, (1949).

[101] A.B.D. Cassie and S. Baxter, "Wettability of porous surfaces," Transactions of the Faraday Society, 40, pp. 546-551, (1944).

[102] D. Camuffo, "Condensation-evaporation cycles in pore and capillary systems according to the Kelvin model", Water, Air and Soil Pollution, 21, pp. 151-159 (1984).

[103] J.W. Rose, and L.R. Glicksman, "Dropwise condensation the distribution of drop sizes" Int. J. Heat Mass Transfer, 16, pp. 411-425 (1973).

[104]E.J. Le Fevre, J.W. Rose, "A theory of heat transfer by dropwise condensation", Proceedings of 3rd International Heat Transfer Conference, 2, Chicago, pp. 362-375, 1966.

[105] Y.J. Song, D.Q. Xu, J.F. Lin and S.X. Tsian, "A study on the mechanism of dropwise condensation," Int. J. Heat Mass Transfer, 34, pp. 2827-2832 (1991).

[106] J. W. Rose, "Dropwise condensation Theory and experiment:: a review", Proc. Instn. Mech. Engrs., 216, pp. 115-128 (2002).

[107]P.J. Marto, D.J. Looney, J.W. Rose, A.S. Wanniarachchi, "Evaluation of organic coatings for the promotion of dropwise condensation of steam," International Journal of Heat and Mass Transfer, 29(8), pp. 1109-1117 (1986).

[108] S. Vemuri, K.J. Kim, B.D. Wood, S. Govindaraju, T.W. Bell "Long term testing for dropwise condensation using selfassembled monolayer coatings of n-octadecylmercaptan" Applied Thermal Engineering, 26(4), pp. 421-429 (2006).

[109] X. Ma, J. Chen, D. Xu, J. Lin, C. Ren, Z. Long, "Influence of processing conditions of polymer film on dropwise condensation heat transfer" Int. J. Heat Mass Transfer, 45(16), pp. 3405-3411 (2002).

[110] Q. Zhao, D.C. Zhang, J.F. Lin, "Surface materials with dropwise condensation made by ion implantation technology", International Journal of Heat and Mass Transfer, 34(11), pp. 2833-2835, (1991).

[111] A.B. Kananeh, M.H. Rausch, A.P. Fröba, A. Leipertz, "Experimental study of dropwise condensation on plasmaion implanted stainless steel tubes", International Journal of Heat and Mass Transfer, 49, pp. 5018-5026 (2006) 
[112] A.B. Kananeh, M.H. Rausch, A. Leipertz, A.P. Fröba, "Dropwise condensation heat transfer on plasma-ionimplanted small horizontal tube bundles," Heat Transfer Engineering, 31(10), pp. $821-828$ (2010).

[113] S. Wang, Y. Zhang, N. Abidi, L. Cabrales, "Wettability and surface free energy of graphene films", Langmuir, 25(18), pp. 11078-11081, (2009).

[114] J. Rafiee, M.A. Rafiee, Z. Yu, N. Koratkar, "Superhydropphobic to superhydrophilic wetting control in graphene films", Advanced Materials, 22, pp. 2151-2154, (2010).

[115] B. Bhushan, Y.C. Jung, "Natural and biomimetic artificial surfaces for superhydrophobicity, self-cleaning, low adhesion, and drag reduction," Progress in Materials Science, 56(1), pp. 1-108 (2011).

[116] J.L. Zhang, J.A. Li, Y.C. Han, "Superhydrophobic PTFE Surfaces by Extension" Macromol Rapid Commun, 25, pp. 1105-1108 (2004).

[117] J. Shiu, C. Kuo, P. Chen, C. Mou, "Fabrication of Tunable Superhydrophobic Surfaces by Nanosphere Lithography" Chem Mater, 16, pp. 561-564 (2004).

[118] L. Xu, W. Chen, A. Mulchandani, Y. Yan, "Reversible Conversion of Conducting Polymer Films from Superhydrophobic to Superhydrophilic" AngewChemInt Ed, 44, pp. 6009-6012 (2005).

[119] M. T. Khorasani, H. Mirzadeh, Z. Kermani, "Wettability of Porous Polydimethylsiloxane Surface : Morphology Study" Appl Surf Sci, 242, pp. 339-345 (2005).

[120] L. Huang, S.P. Lau, H.Y. Yang, E.S.P. Leong, S. F. Yu, "Stable Superhydrophobic Surface via Carbon Nanotubes Coated with a ZnO Thin Film" J PhysChem, 109, pp. 7746-7748 (2005).

[121] Y.C. Jung, B. Bhushan, "Mechanically Durable CNTComposite Hierarchical Structures with Superhydrophobicity, Self-Cleaning, and Low-Drag", ACS Nano, 3, pp. 41554163 (2009).

[122] K.K.S. Lau, J. Bico, K.B.K. Teo, "Superhydrophobic carbon nanotube Forests" Nano Lett, 3, pp. 1701-1705 (2003).

[123]B. Bhushan, "Biomimetics: lessons from nature - an overview", Philosophical Transactions of the Royal Society A, 367, 1445-1486 (2009).

[124] W. Choi, A. Tuteja, J.M. Mabry, R.E. Cohen, G.H. McKinley, "A modified Cassie-Baxter relationship to explain contact angle hysteresis and anisotropy on nonwetting textured surfaces", Journal of Colloid and Interface Science, 339, pp. 208-216 (2009).

[125] M. Nosonovsky, and B. Bhushan, "Patterned nonadhesive surfaces: superhydrophobic and wetting regime transitions" Langmuir, 24, pp. 1525-1533 (2008).

[126] Y.C. Jung, B. Bhushan, "Wetting transition of water droplets on superhydrophobic patterned surfaces", ScriptaMaterialia, 57, pp. 1057-1060, (2007).

[127] Y. T. Cheng, D. E. Rodak, A. Angelopoulos, T. Gacek,
"Microscopic observations of condensation of water on lotus leaves" Appl. Phys. Lett, 87, 194112 (2005).

[128] Y.T. Cheng, and D.E. Rodak, "Is the lotus leaf superhydrophobic?," Appl. phys. Lett., 86, 144101 (2005).

[129] Y. Zheng, D. Han, J. Zhai, L. Jiang, "In situ investigation on dynamic suspending of microdroplet on lotus leaf and gradient of wettable micro- and nanostructure from water condensation", Applied Physics Letter, 92, 084160, (2008).

[130] K.A. Wier, and T.J. McCarthy, "Condensation on ultrahydrophobic surfaces and its effect on droplet mobility: ultrahydrophobic surfaces are not always water repellant," Langmuir, 22, pp. 2433-2436 (2006).

[131] K.K. Varanasi, M. Hsu, N. Bhate, W. Yang, and T. Deng, "Spatial control in the heterogeneous nucleation of water" Appl. Phys. Lett., 95, 094101 (2009).

[132] J.B. Boreyko, and C. H. Chen, "Self-propelled DropwiseCondesate on Superhydrophobic Surfaces" Phys. Rev. Lett., 103, 184501 (2009).

[133] C. Dietz, K. Rykaczewski, A. G. Fedorov, and Y. Joshi, "Visualization of droplet departure on a superhydrophobic surface and implications to heat transfer enhancement during dropwise condensation" Appl. Phys. Lett., 97, 033104 (2010).

[134] J. W. Rose, "Condensation heat transfer fundamentals" Chemical Engineering Research and Design, 76, pp.143152 (1998).

[135] Schmidt, E., Schurig, W., Sellschop, W., Versucheuber die Kondensation von Wasserdampf in Film- und Tropfenform, Tech MechThermodynamik (ForschungIng Wes), 1, pp.52-63 (1930).

[136] X. Ma and J. W. Rose, "Advances in dropwise condensation heat transfer: Chinese research," Chem. Eng. J., 78, pp. 87-93 (2000).

[137] B. J. Chung, S. Kim, and M. C. Kim, "Experimental comparison of film-wise and drop-wise condensation of steam on vertical flat plates with the presence of air", Int. Comm. Heat Mass Transfer, 31, pp. 1067-1074 (2004).

[138]B. J. Chung, and S. Kim, "Film condensations on horizontal and slightly inclined upward and downward facing plates" Heat Transfer Engineering, 29, pp. 936-941 (2008).

[139] B.J Chung, M.C. Kim, M. Ahmadinejad, "Film-wise and Drop-wise condensation of steam on short inclined plates", Journal of Mechanical Science and Technology, 22, pp. 127-133 (2008).

[140] S. Vemuri, and K. J. Kim, "An experimental and theoretical study on the concept of dropwise condensation" Int. J. Heat Mass Transfer, 49, pp. 649-657 (2006).

[141] Junjie Yan, Yeusen Yang, Shenhua Hu, Kejian Zhen, and Jiping Liu, "Effects of vapor pressure/velocity and concentration on condensation heat transfer for steamethanol vapor mixture" Int. J. Heat Mass Transfer, 44, pp. 51-60 (2007). 